\title{
La envolvente en la rehabilitación de conjuntos de vivienda protegida
}

\author{
Noelia Cervero Sánchez ${ }^{1}$
}

Recibido: 27-09-2019 | en su versión final: 20-12-2019

Resumen En este artículo se trata la renovación de la envolvente de la edificación residencial en conjuntos urbanos de vivienda protegida construidos entre los años cuarenta y setenta del siglo XX. El estado y funcionamiento de la envolvente de esta edificación vulnerable condicionan su estabilidad, habitabilidad, eficiencia energética e identidad arquitectónica, con su efecto en el desarrollo equilibrado de la ciudad. La investigación se centra en una de las primeras rehabilitaciones integrales que se han completado con un alcance territorial en España, la desarrollada en el Poblado Dirigido de Caño Roto, Madrid, entre los años 1994 y 2004. La metodología utilizada plantea un pormenorizado análisis cualitativo y cuantitativo de la adecuación funcional de la envolvente térmica en el momento previo a la rehabilitación, que da lugar a un diagnóstico, y en el momento actual, que permite evaluar el resultado. Ambos estados se estructuran en función de los cerramientos de cubierta, fachada y suelo, según la definición que hace de envolvente térmica el Código Técnico de la Edificación y aplicando sus baremos para obtener una evaluación objetiva y actual. El estudio sistemático de la intervención en la envolvente constata que el proceso de rehabilitación ha conseguido unos parámetros óptimos, que contribuyen a la renovación del parque edificatorio a escala urbana, pero supone la alteración de su imagen con la consiguiente pérdida de valor patrimonial o interés arquitectónico. Este resultado lleva a cuestionar las pautas y principios de estas operaciones, que por su relativa novedad no cuentan con una normativa propia.

Palabras clave: Edificación; eficiencia; patrimonio; Caño Roto

Citación

Cervero Sánchez, N. (2020). La envolvente en la rehabilitación de conjuntos de vivienda protegida, ACE: Architecture, City and Environment, 14(42), 8960. DOl: http://dx.doi.org/10.5821/ace.14.42.8960

\footnotetext{
1 Dra. Arquitecta. Profesora Ayudante Doctora, Departamento de Arquitectura, Escuela de Ingeniería y Arquitectura, Universidad de Zaragoza (ORCID: 0000-0002-1916-5812, Researcher ID: 0-9182-2015, Scopus ID: $\underline{5646556400}$ ). Correo de contacto: ncervero@unizar.es
}

ACE, 14 (42) CC BY-ND 3.0 ES | UPC Barcelona, España | La envolvente en la rehabilitación de conjuntos de vivienda protegida . DOI: http://dx.doi.org/10.5821/ace.14.42.8960 


\section{The building envelope in the rehabilitation of affordable housing estates}

Abstract

This paper studies the rehabilitation of the residential building envelope in urban affordable housing estates built between the forties and the seventies of the twentieth century. The state and functioning of the envelope of this vulnerable building condition its stability, habitability, energy efficiency and architectural identity, with its effect on the balanced development of the city. The research is carried out by assessing one of the first urban rehabilitations that have been completed in Spain, in the Poblado Dirigido de Caño Roto, Madrid, between 1994 and 2004. The methodology used raises a detailed qualitative and quantitative analysis of the functional adequacy of the thermal envelope prior to rehabilitation, which results in a diagnosis, and at the current time, which allows an evaluation. Both states are structured in a study of the enclosure structured in the roof, facade and floor, according to the definition of thermal envelope issued by the Spanish Technical Building Code (Código Técnico de la Edificación) and applying its scales to obtain an objective and current evaluation. The systematic study of the envelope improvement confirms that the rehabilitation process has achieved optimal parameters, which contribute to the renovation of the urban housing stock, but it implies the alteration of its image with the consequent loss of heritage value or architectural interest. This result leads to question the guidelines and principles of these operations, and the need of their own regulations.

Keywords: Building; efficiency; heritage; Caño Roto

\section{Introducción}

En la búsqueda de un desarrollo equilibrado de la ciudad la edificación residencial ha de reunir condiciones aceptables de habitabilidad, relacionada con el confort y la seguridad, y adaptarse a los requerimientos de eficiencia energética1. Las características constructivas y el estado de conservación de los conjuntos residenciales determinan su calidad como patrimonio construido, y sus parámetros funcionales condicionan los estándares de vida de la población y su repercusión medioambiental ${ }^{2}$. Tradicionalmente, la normativa española ha mostrado un escaso interés por limitar el consumo energético de la edificación. La primera normativa que introduce unos criterios mínimos de eficiencia edificatoria ${ }^{3}$ es la Norma Básica de la Edificación relativa a Condiciones Térmicas NBE-CT-79, cuyas exigencias energéticas se endurecen con la aprobación del Código

\footnotetext{
${ }^{1}$ Asegurando con ello un desarrollo sostenible, en el sentido de lograr un estándar de vida mínimo y adecuado para todos los habitantes de la ciudad (Campos-Sánchez, Abarca-Álvarez y Domingues, 2018), en el que la edificación resulte eficiente y eficaz, en relación con el confort conseguido y el impacto ambiental causado para alcanzarlo (Quesada, 2018).

2 Según Albert Cuchí (2014), las inversiones en la rehabilitación de edificios pueden ahorrar energía, reducir gastos, mejorar la productividad y confort, e incrementar la utilidad y valor del inmueble.

3 Se adopta como consecuencia del Real Decreto 1490/1975, de 11 de julio, para acometer los problemas derivados del encarecimiento de la energía tras la crisis de 1973.
} 
Técnico de la Edificación (CTE) en 2006 y sus sucesivas actualizaciones, que recogen la aplicación de las Directivas Europeas de reducción de gases de efecto invernadero ${ }^{4}$.

Esta circunstancia ha dado lugar a un parque inmobiliario de escasa calidad, del que edificaciones como las existentes en los conjuntos de vivienda protegida construidos entre los años cuarenta y setenta del siglo XX pueden constituir casos de extrema vulnerabilidad, y cuya actualización resulta importante por su escala urbana. Sus características constructivas son variables, en función de su fecha de construcción y el perfil de la población al que van destinadas (Blos, 1999), pudiendo generalizar una escasa calidad de las promociones construidas hasta la década los años cincuenta, incluido el Plan de Urgencia Social de 1958, como consecuencia de la escasez de materiales, la precariedad de los procesos de construcción y la extrema limitación de los presupuestos (Sambricio, 2000). A estas condiciones de partida, se suma una falta de mantenimiento, cualidad común a todos los conjuntos del periodo, que incide negativamente en la durabilidad de la edificación (Díaz Gómez, 1986). Hay que hacer alusión además a otros factores de carácter social asociados a la idiosincrasia, vulnerabilidad, arraigo, tipo de tenencia, etc. de sus habitantes, que en muchos casos demandan la mejora física de los barrios.

Las intervenciones enfocadas a la actualización de estos conjuntos residenciales de promoción pública con el objeto de aportarles una segunda vida ${ }^{5}$, evolucionan hacia una progresiva diversificación de actuaciones. En un primer periodo que comienza en los años setenta, el Estado pone en marcha medidas de urgencia, que consisten en programas de mantenimiento de las edificaciones, con actuaciones sistematizadas para mejorar sus condiciones de seguridad estructural, y programas de renovación urbana. En función de las particularidades de cada conjunto, a partir de mediados la década de los años noventa predominan operaciones planificadas y complejas, en las que pueden coexistir medidas mixtas de renovación-rehabilitación o actuaciones de rehabilitación integral que suponen una reestructuración profunda de la edificación o una actualización funcional de la misma (Díaz, et al., 2019). En ellas prima la conservación de la edificación y su actualización según los requerimientos de la normativa vigente para obra nueva, en la medida en la que resultan alcanzables y compatibles (Casals y Arcas, 2010). Al tratarse de operaciones con carácter territorial, es decir aplicadas a ámbitos urbanos de la ciudad, la dificultad de gestión y financiación condiciona su desarrollo ${ }^{6}$, dando lugar a procesos prolongados que en reducidas ocasiones se ejecutan en su totalidad. En España, uno de los primeros casos de rehabilitación integral que se completa es la rehabilitación del Poblado Dirigido de Caño Roto, en Madrid, entre los años 1994 y 2004.

La construcción del Poblado Dirigido de Caño Roto, de 1.606 viviendas, obra de los arquitectos Antonio Vázquez de Castro y José Luis íñiguez de Onzoño, se lleva a cabo entre los años 1957 y 1963, acogida al marco legislativo de la Ley de 15 de julio de 1954 de viviendas de Renta Limitada

\footnotetext{
4 La Unión Europea apuesta fuertemente por la reducción de energía en el sector de la edificación desde los años noventa, como muestran las Directivas 1993/76/CE y 2002/91/CE, que concretan líneas de acción. Asimismo, con objeto de cumplir el Protocolo de Kioto, aprobado por la ONU en 1998 para estabilizar las concentraciones de gas de efecto invernadero, en 2009 la Unión Europea establece una serie de objetivos conocidos como Paquete 20-20-20 Energía y Cambio Climático. De manera más reciente, la Directiva 2018/2002 de 11 de diciembre de 2018, que modifica la Directiva 2012/27/UE establece la obligatoriedad de alcanzar durante el periodo 2021-2030 un ahorro anual de al menos 0,8\% de energía final y muestra su compromiso con los hogares que sufren pobreza energética.

${ }^{5}$ La terminología que conlleva este tipo de intervenciones urbanas es frecuentemente usada de manera ambigua y equívoca por la bibliografía y la legislación. Teniendo en cuenta las reflexiones realizadas en el ámbito académico (Moya y Díez, 2012), en este artículo se denominan: renovación o remodelación, cuando implican una sustitución de la edificación atendiendo a una nueva ordenación urbanística; renovación-rehabilitación, cuando se combinan distintos niveles de actuación que pueden variar desde la remodelación a la rehabilitación ligera; y rehabilitación, cuando suponen la mejora las condiciones de seguridad y habitabilidad de la edificación y del espacio público.

6 Esta realidad requiere que los procesos se ejecuten mediante mecanismos específicos liderados por las administraciones, cuestión que conlleva una firme apuesta política (Rubio y Molina, 2010) y una demanda previa, formal y organizada por parte de los propietarios (Tejedor, 2015).
} 
con Ordenanzas técnicas y Normas constructivas de 1955. La edificación residencial se rige por una ordenación ortogonal en función de la topografía y el soleamiento, que conjuga tipologías edificatorias en altura, de carácter colectivo, y en superficie, de carácter unifamiliar. Las viviendas colectivas se organizan en bloques lineales de $\mathrm{PB}+3$ y $\mathrm{PB}+5$ alturas correspondientes a los tipos $1 \mathrm{~A}$ y 1DEFG, y en torres de PB+5 alturas del tipo 1BC, y las viviendas unifamiliares de $\mathrm{PB}+1$, pertenecen a los tipos 2A, 2BC y 2S (Figura 1).

Figura 1. Planta general y emplazamiento de las tipologías edificatorias

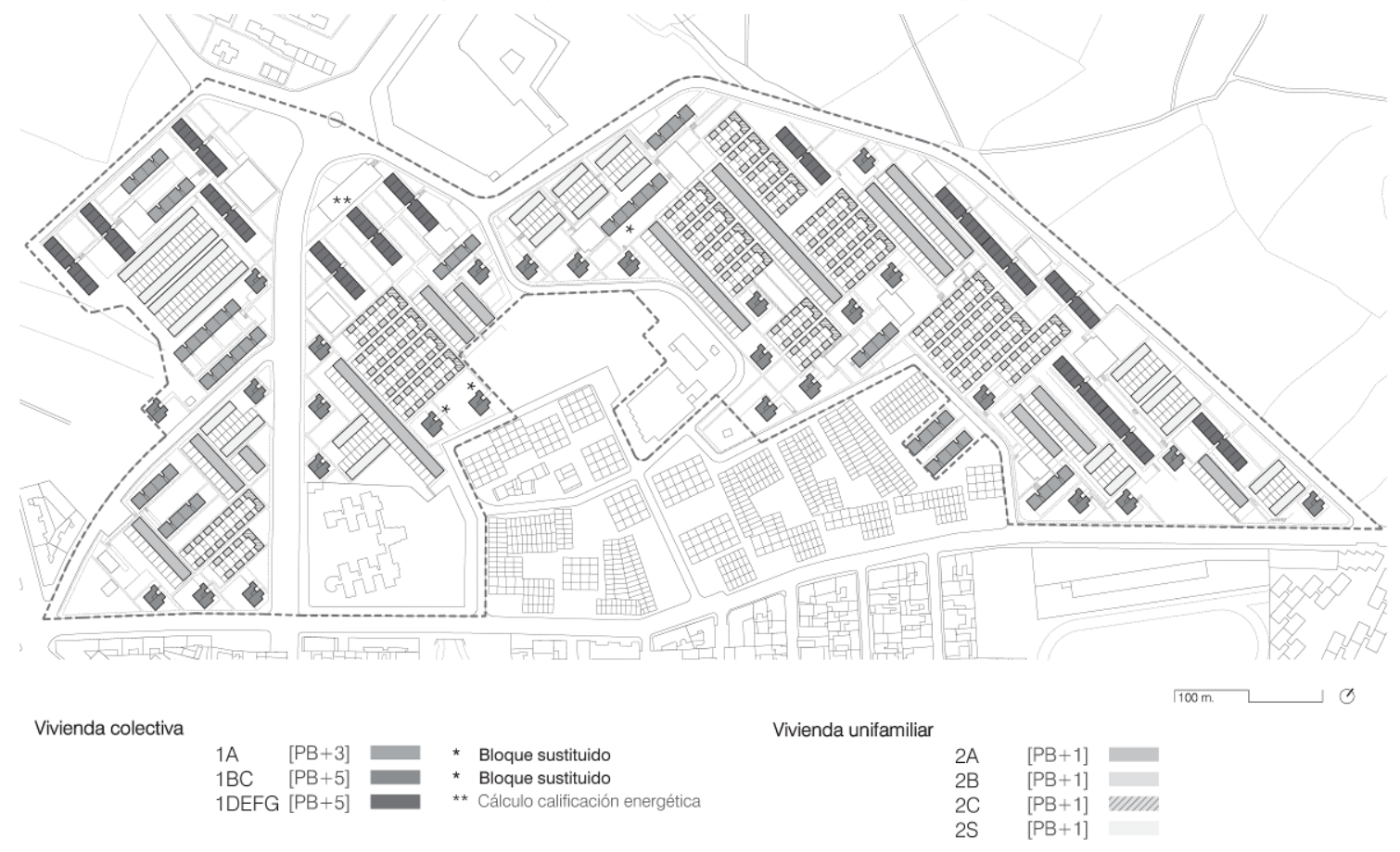

Fuente: Elaboración propia.

El sistema constructivo de las viviendas, condicionado por la economía y la racionalidad, aporta soluciones que buscan optimizar la interpretación de la normativa a través de nuevas fórmulas compositivas para conseguir una mayor eficacia (Cánovas y Ruiz, 2013). Como requisito esencial, se busca que la construcción del poblado pueda ser llevada a cabo por mano de obra no especializada: empresas constructoras de pequeña entidad con escasa cualificación y los propios habitantes, que recurren al sistema de prestación personal en las viviendas unifamiliares del tipo 2S. Se huye con ello de la prefabricación y la mecanización de medios auxiliares, en favor de sistemas tradicionales, con una rígida coordinación y control técnico que garantizan unas condiciones mínimas (F. Galiano, F. de Isasi y Lopera, 1989).

Estas características constructivas contrastan con las espaciales y volumétricas del poblado que constituye, en palabras de Juan Daniel Fullaondo (1969, pág. 34) "la obra cumbre de la experiencia social madrileña”. Su morfología urbana y configuración compositiva y tipológica muestran el resultado de la investigación que en la década de los años cincuenta incorpora la modernidad a la realidad española, y es considerada por las publicaciones especializadas nacionales e internacionales como un referente ${ }^{7}$ (Figura 2).

\footnotetext{
7 Sin embargo, su catalogación patrimonial, cuyos orígenes datan de 1977, no tuvo una gran relevancia ni valor oficial (Díez de Pablo, 2015).
}

ACE, 14 (42) CC BY-ND 3.0 ES | UPC Barcelona, España | La envolvente en la rehabilitación de conjuntos de vivienda protegida . DOI: http://dx.doi.org/10.5821/ace.14.42.8960 


\section{ACE Architecture, City and Environment}

E-ISSN 1886-480

Figura 2. Estado inicial. Tipologías y vistas de la edificación en 1963 y 1994

BLOQUE 1A

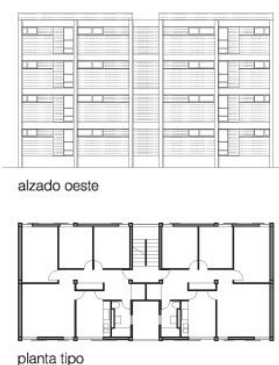

TORRE 1BC

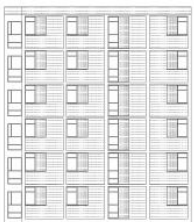

alzado sur
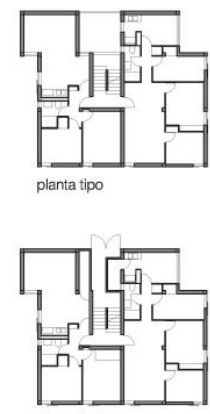

planta baja

BLOQUE 1DEFG
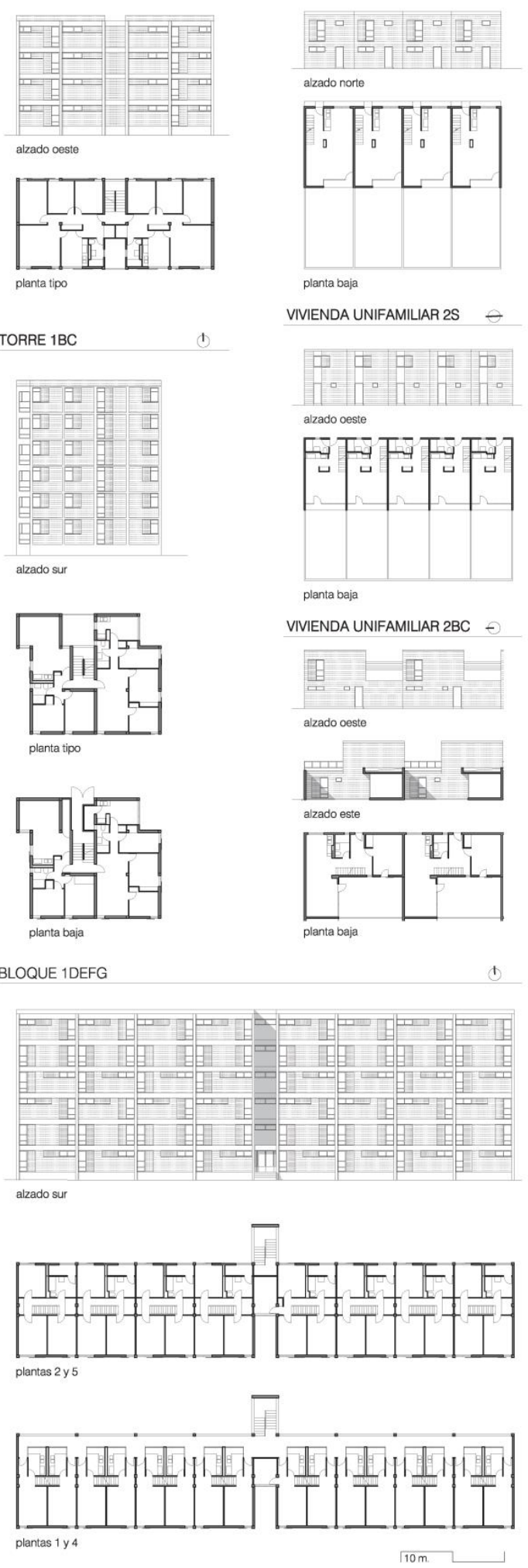

VIVIENDA UNIFAMILIAR $2 S-\vartheta$

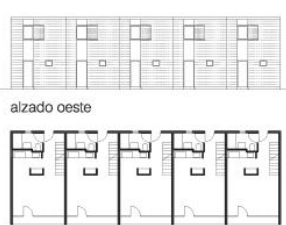

planta baja

VIVIENDA UNIFAMILIAR 2BC -
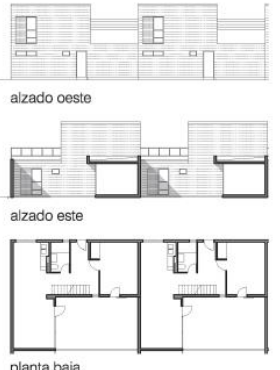

uente: Elaboración propia.
BLOQUE 1A

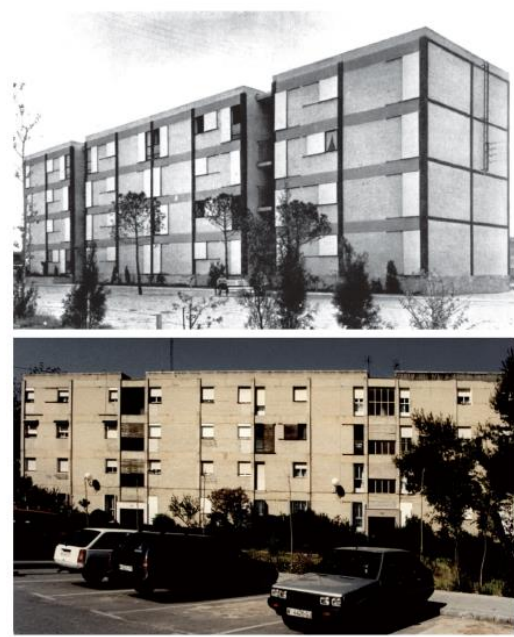

TORRE 1BC
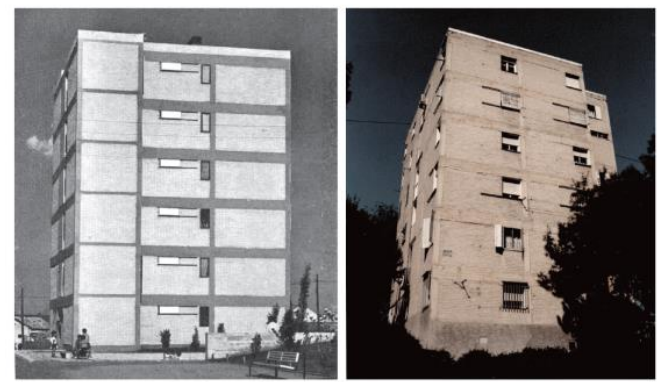

BLOQUE 1DEFG

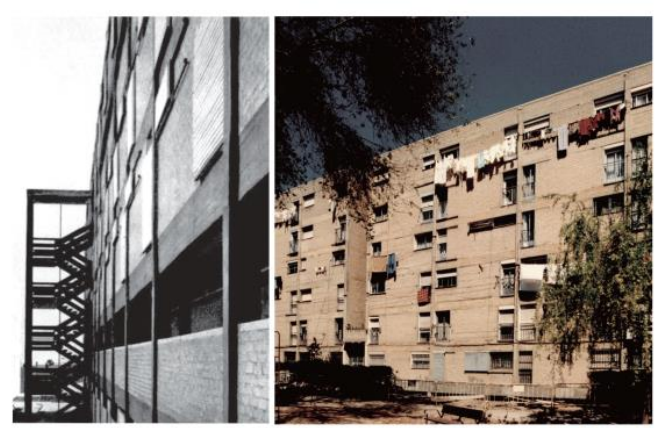

VIVIENDA UNIFAMILIAR 2A

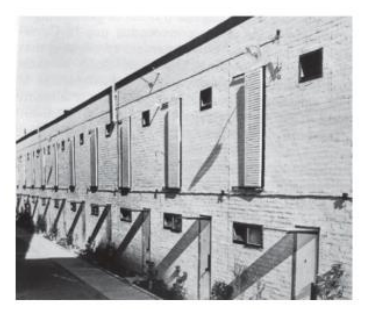


A pesar de ello, la detección de asientos diferenciales en las cimentaciones desde las últimas fases de construcción del poblado, obliga a llevar a cabo intervenciones locales de recalce ${ }^{8}$, que salvo excepciones aisladas, estabilizan la edificación?. En 1992 existen sin embargo problemas estructurales localizados en bloques y en hileras de viviendas unifamiliares, principalmente situadas en ladera ${ }^{10}$. Tras una larga reivindicación de la situación del conjunto por parte de la población, en la que, junto a la alarma por problemas de estabilidad, se acusaban importantes problemas funcionales en la edificación, la rehabilitación se realiza en base a proyecto de los arquitectos Eduardo Hernández Fernández, José Luis López Delgado y Gerardo Ruiz Palomeque, entre 1994 y 2004.

Para asegurar la seguridad de la edificación, se hacen imprescindibles micropilotajes y recalces puntuales, y la sustitución de tres bloques que presentan un estado crítico ${ }^{11}$ (Figura 1), y en el resto ${ }^{12}$ se llevan a cabo las acciones necesarias para lograr su adecuación estructural y funcional a la normativa vigente para obra de nueva planta equivalente (Ruiz Palomeque, 2001). La adecuación estructural supone: estabilización de asientos en cimentación; reparación de las estructuras de hormigón; y refuerzo de los muros de carga con mejora de su rigidez y condiciones de apoyo. La adecuación funcional implica: seguridad frente a accidentes y siniestros con fijación de paños de fachada y sustitución de petos de cubierta en mal estado; mejora de la estanqueidad y aislamiento térmico de la envolvente; aislamiento acústico en relación con el exterior y entre zonas comunes y viviendas; renovación de las redes generales de instalaciones hasta su acometida a las viviendas; dotación de accesos practicables y adaptación de recorridos a través de las zonas comunes e instalación de ascensores en los edificios de seis plantas (Figura 3).

Este artículo plantea un análisis de la adecuación funcional de la envolvente térmica de la edificación para conocer su composición y estado en el momento previo a la rehabilitación, que dará lugar a un diagnóstico, y en el momento actual, que permitirá evaluar su resultado. Frente al resto de actuaciones, su papel es relevante debido a que, además de contribuir a la consolidación de la edificación, aporta una mejora de sus condiciones higrotérmicas interiores, generando en el usuario una sensación de bienestar y satisfacción que el CTE denomina confort, y reduce la demanda energética ${ }^{13}$, compuesta en un alto porcentaje por la energía consumida en calefacción y

\footnotetext{
${ }^{8}$ Se hacen necesarios en 1961 Proyectos Adicionales de cimentaciones complementarias a los Proyectos de las fases primera y segunda.

${ }^{9}$ La existencia de asientos diferenciales se debe a problemas puntuales causados por: espesores de relleno, en los que la cimentación no llega al suelo natural; fugas en las conducciones, que dan lugar a un ablandamiento del terreno o de los rellenos procedentes de escorias y de restos de edificaciones previas, más sensibles a la acción del agua; o antiguas corrientes de agua sobre las que se sitúa la edificación.

10 Como se refleja en dos informes, uno encargado por la Asociación de Vecinos a los arquitectos que terminan realizando la rehabilitación y por la Dirección General de Arquitectura de la Comunidad de Madrid a Aroca Asociados y Euroconsult. Junto a las patologías derivadas de la cimentación, la estructura de los bloques acusa el efecto de errores y precipitación en su ejecución. Los pórticos presentan secciones de armadura coherentes y un límite elástico suficiente, pero se detecta ausencia de estribos, barras arqueadas, solapes y recubrimientos reducidos y disposición incorrecta de armaduras y estribos. El hormigón, compuesto por áridos de gran tamaño como era habitual en la época, muestra una resistencia escasa, constituyendo el elemento más crítico de la estructura. Con respecto a los forjados, se diagnostica un buen comportamiento, a pesar de la falta de armadura de reparto y solicitaciones debidas a movimientos de la cimentación.

${ }^{11}$ La edificación con mayor grado de deterioro es la situada sobre antiguos cauces. Las actuaciones más extremas se llevan a cabo en la edificación en altura, con la sustitución de un bloque tipo 1A y dos tipos 1BC, uno de ellos como respuesta a una situación de emergencia, debido a la colisión de un camión meses antes del comienzo de la rehabilitación integral del poblado.

${ }^{12}$ Se adhieren a la intervención el total de la edificación en altura y un 30\% de las viviendas unifamiliares, lo que supone 1.165 viviendas.

13 La Asociación Nacional de Industrias de Materiales Aislantes (ANDIMA, 2008) cuantifica que un aislamiento adecuado en cubierta puede suponer un ahorro energético del 4-14\% del consumo total del edificio (10-22\% sobre el consumo de climatización) y en fachada, del 5-16\% sobre el consumo total del edificio (15-24\% sobre el consumo de climatización), aumentando sus beneficios en climas extremos y por tanto con mayores demandas.
} 
refrigeración a lo largo del año ${ }^{14}$ (de Luxán, 2010). Desde el punto de vista formal, supone una transformación de la imagen de la edificación en base a criterios constructivos muy diferentes de los adoptados en el proyecto original. En consecuencia, se evalúa la mejora funcional de la envolvente en la edificación y los efectos que produce, y se plantea una reflexión sobre la pérdida del valor patrimonial o del interés arquitectónico que la rehabilitación puede implicar para la obra.

\section{Metodología}

La edificación del Poblado Dirigido de Caño Roto se construye tomando como referencia las Normas Constructivas de las viviendas de Renta Limitada de 1955 y se rehabilita con el cumplimiento de condiciones térmicas de la Norma Básica de la Edificación NBE-CT-79, con el objeto de aportar un comportamiento semejante al exigido en obra nueva. En este artículo se analiza la intervención aplicándole una óptica actual, por lo que se estudian los estados inicial y modificado según los requerimientos del CTE, lo que permite evaluar la mejora higrotérmica y energética alcanzadas tomando como referencia el horizonte presente y establecer una comparación objetiva entre ambos estados.

En la actualidad, la rehabilitación de la envolvente de un edificio existente se regula por el Documento Básico de Limitación de demanda energética HE 1 (DB-HE 1) del CTE, bajo supuestos de obra nueva. Establece que cuando las obras afectan a más del 25\% de la envolvente térmica, la demanda energética conjunta del edificio ha de cumplir la limitación, como especifica el Apartado 2.2.2.1. del $D B-H E$ 1, y en el resto de los casos, llegar a los valores máximos para que las actuaciones sean coherentes con las condiciones del edificio: "[...] se aplicará a las obras de ampliación, modificación, reforma o rehabilitación que se realicen en edificios existentes, siempre y cuando dichas obras sean compatibles con la naturaleza de la intervención y, en su caso, con el grado de protección que puedan tener los edificios afectados. La posible incompatibilidad de aplicación deberá justificarse en el proyecto y, en su caso, compensarse con medidas alternativas que sean técnica y económicamente viables".

Los elementos a analizar en este estudio se extraen de la definición que hace de envolvente térmica el Documento Básico DB-HE 1 del CTE en su Apartado 5.2.1.: "[...] está compuesta por todos los cerramientos que delimitan los espacios habitables con el ambiente exterior, terreno $u$ otro edificio, y por todas las particiones interiores que delimitan los espacios habitables con no habitables en contacto con el ambiente exterior". De tal manera que el análisis se estructura en función de los siguientes cerramientos: cubierta, fachada y suelo (cerramiento en contacto con el terreno, en contacto con el aire, partición horizontal con cámara sanitaria y partición horizontal con espacio no habitable) $)^{15}$.

Cada uno de estos cerramientos se analiza de manera independiente mediante una descripción gráfica y constructiva ${ }^{16}$ y se localiza en las distintas tipologías edificatorias, teniendo en cuenta qué tipo de espacio interior delimita: espacio habitable acondicionado o zona común.

\footnotetext{
${ }^{14}$ En España la energía consumida por los hogares en 2017 supone el 18,13\% del total, según datos del Instituto para la Diversificación y Ahorro de la Energía (IDAE), ascendiendo en cada uno de ellos el consumo medio de energía en calefacción, variable en función de la zona geográfica, a un 47\% (IDAE, 2011).

15 Las particiones verticales con espacios no habitables se tienen en cuenta en los cálculos, pero no entran en las comparativas, por no ser equiparables a los cerramientos exteriores.

16 Para obtener la resistencia térmica total, se define cada una de las capas: espesor [e (m)] / masa por superficie [m $(\mathrm{kg} / \mathrm{m} 2)]$ / conductividad $[\lambda(\mathrm{W} / \mathrm{mK})]$ / resistencia térmica $[\mathrm{R}(\mathrm{m} 2 \mathrm{~K} / \mathrm{W})]$. Y las cámaras de aire: espesor $[\mathrm{e}(\mathrm{m})]$ / resistencia térmica $[R(\mathrm{~m} 2 \mathrm{~K} / \mathrm{W})]$. Los valores característicos de los distintos materiales y productos se consultan en el Catálogo de elementos constructivos del CTE y en los Proyectos constructivos del conjunto.
} 


\section{ACE Architecture, City and Environment}

Figura 3. Estado modificado. Tipologías y vistas de la edificación en 2019

BLOQUE 1A

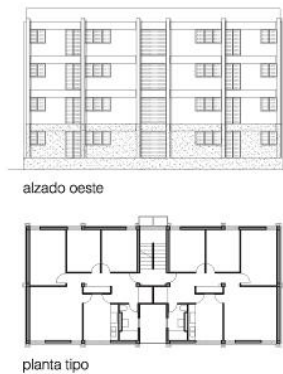

TORRE 1BC

\begin{tabular}{|c|c|}
\hline 梱 & प1] \\
\hline 霜 & 啫 \\
\hline 而田 & 四 \\
\hline 政 & प1I \\
\hline 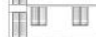 & ए \\
\hline 成业 & प1 \\
\hline
\end{tabular}

alzado sur
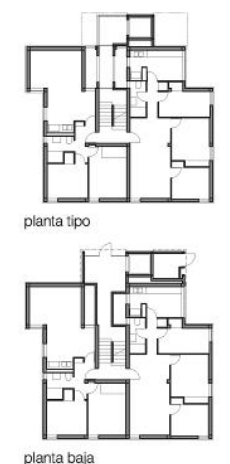

BLOQUE 1DEFG
VIVIENDA UNIFAMILIAR 2A

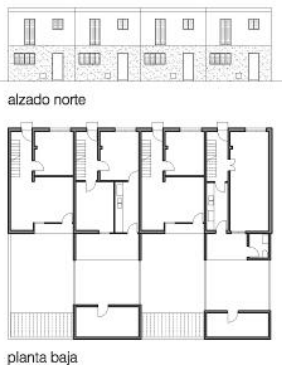

VIVIENDA UNIFAMILIAR $2 S \quad \theta$

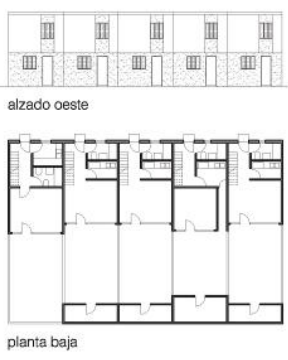

VIVIENDA UNIFAMILIAR 2BC -
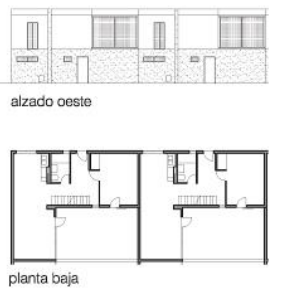

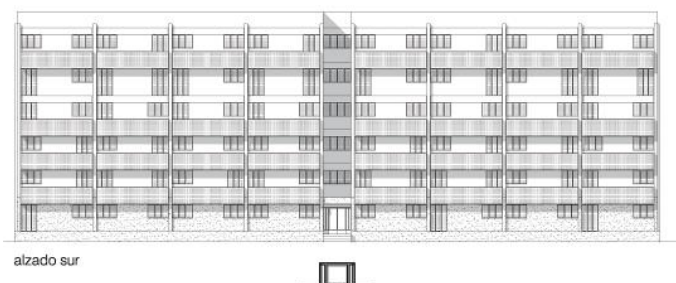

प11
$\square$

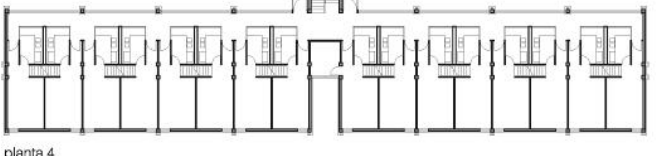

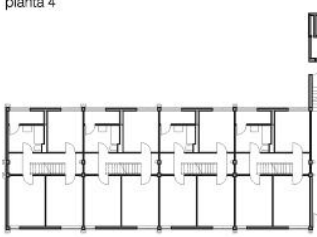

planta baja

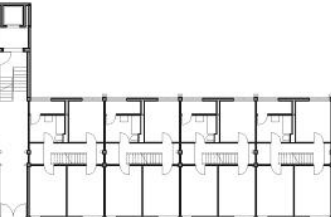

$10 \mathrm{~m}$

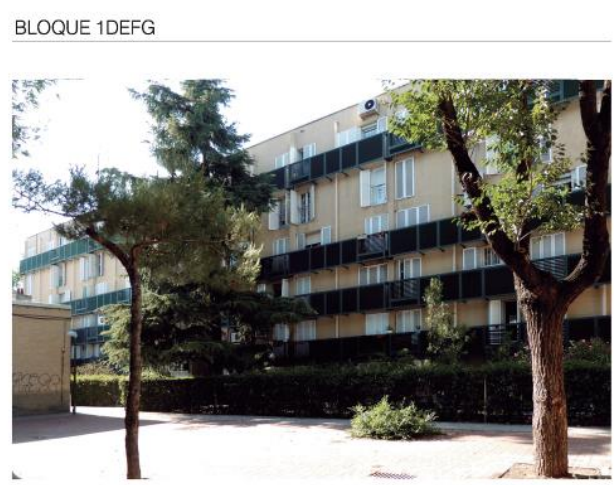

VIVIENDA UNIFAMILIAR 2A

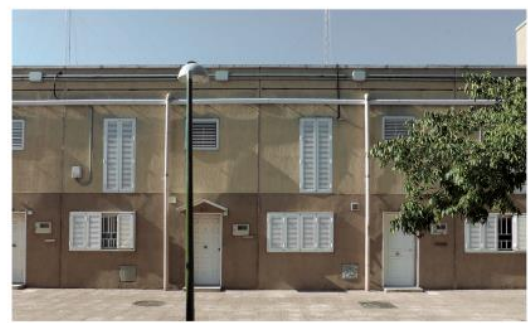

Fuente: Elaboración propia. 
La valoración higrotérmica global de la envolvente se realiza analizando la transmitancia térmica, y el riesgo de condensaciones superficiales en los cerramientos y en los puentes térmicos.

- Transmitancia térmica $\left[U\left(\mathrm{~W} / \mathrm{m}^{2} \mathrm{~K}\right)\right]$. Su cálculo y valoración, que se realizan según los métodos simplificados que se describen en el Documento de Apoyo al DB-HE 1 (DA DB-HE 1), se complementa con la transmitancia térmica de los huecos $\left[U_{H}\left(\mathrm{~W} / \mathrm{m}^{2} \mathrm{~K}\right)\right]$, que se calcula igualmente en base al DA DB-HE 1 del CTE.

Esta referencia sirve para tener una perspectiva actual y un valor único que permite establecer una comparación entre los estados inicial y modificado.

- Condensaciones superficiales. Su cálculo, según el método del Documento de Apoyo al DB-HE 2 ( $D A D B-H E$ 2), sigue un criterio simplificado que establece un límite máximo del $80 \%$ de humedad relativa media mensual sobre la superficie del cerramiento analizado. Consiste en comprobar que el factor de temperatura de la superficie interior $\left[f_{R s i}\right]$ es superior al mínimo de la superficie interior [ $\left.f_{R s i, m i n}\right]$ para condiciones interiores y exteriores correspondientes al mes de enero de la localidad ${ }^{17}$.

Con los datos obtenidos para cada cerramiento, se hace una comparativa, indicando el porcentaje que supone cada uno de ellos respecto del total, su transmitancia teniendo como referencia el valor máximo aportado por el CTE, y los casos con riesgo de condensación superficial (Kurtz, Monzón y López-Mesa, 2015). De esta manera se ponen en relación, lo que permite sacar conclusiones a nivel de conjunto, al estudiar el comportamiento mayoritario y las variaciones entre los distintos tipos.

- Puentes térmicos. Se estructuran en función de su situación y se analizan de forma gráfica, especificando si existe riesgo de condensación superficial, según el Documento de Apoyo al DB-HE 3 (DA DB-HE 3). Para condiciones similares a las del método de cálculo de condensaciones superficiales y con el factor de temperatura de la superficie interior mínimo [ $f_{R s i, m i n}$, se deduce la temperatura superficial mínima interior aceptable para evitar el riesgo de condensación en todo punto del puente térmico $\left[\theta_{\text {simin }}\left({ }^{\circ} \mathrm{C}\right)\right]^{18}$.

Por último, la evaluación del estado de conservación de la envolvente, se realiza en función de aspectos cualitativos con los que se estudia la situación de los elementos constructivos, las condiciones que garantizan su estabilidad, la naturaleza de las alteraciones sufridas por la edificación y su posible empobrecimiento ${ }^{19}$.

\section{Estado inicial de la envolvente}

La envolvente térmica de la edificación del conjunto, compuesta por sistemas propios de la construcción tradicional, cumple con las disposiciones de las Normas Constructivas de las viviendas de Renta Limitada de 1955, que presentan la composición ${ }^{20}$ y estado de conservación ${ }^{21}$ (Figura 2) que se detallan a continuación.

\footnotetext{
17 El factor de temperatura de la superficie de cada cerramiento, se calcula a partir de su transmitancia térmica y el mínimo, de la clase de higrometría de cada espacio en función del uso, según la norma ISO 13788: 2002, y de la zona climática, según el Apéndice $B$ del DB-HE.

18 El cálculo de la temperatura superficial interior real $\left[\Theta\right.$ si $\left.\left({ }^{\circ} \mathrm{C}\right)\right]$ se realiza mediante el software THERM Finite Element Simulator.

19 Para sistematizarlo, se tienen en cuenta los requisitos normalizados que se establecen en el Informe de evaluación de los edificios, como documento de referencia estatal introducido con la Ley 8/2013, de 26 de junio, de rehabilitación, regeneración y renovación urbanas.

20 Se consulta el Proyecto de primera y segunda fase y los Proyectos Adicionales del Poblado Dirigido de Caño Roto de A. Vázquez de Castro y J.L. İñiguez de Onzoño, 1958 (Archivo del Instituto de la Vivienda de Madrid, IVIMA, signatura: 10797-10802)
} 


\subsection{Cubiertas}

Las cubiertas del poblado son planas de baldosín catalán tomado con mortero sobre impermeabilización, rasilla cerámica para formación de pendiente, cámara de aire ligeramente ventilada conformada por tabiquillos, y forjado guarnecido y enlucido al interior (cubierta 1, e.=0,35 m.). Sobre las zonas comunes de los edificios en altura, exteriores en todas las tipologías, la cubierta no tiene cámara de aire, quedando conformada por baldosín catalán sobre mortero de formación de pendiente, impermeabilización y forjado guarnecido y enlucido (cubierta 2, e.=0,26 m.) (Figura 4).

Figura 4. Estado inicial. Soluciones constructivas de cubierta, fachada y suelo
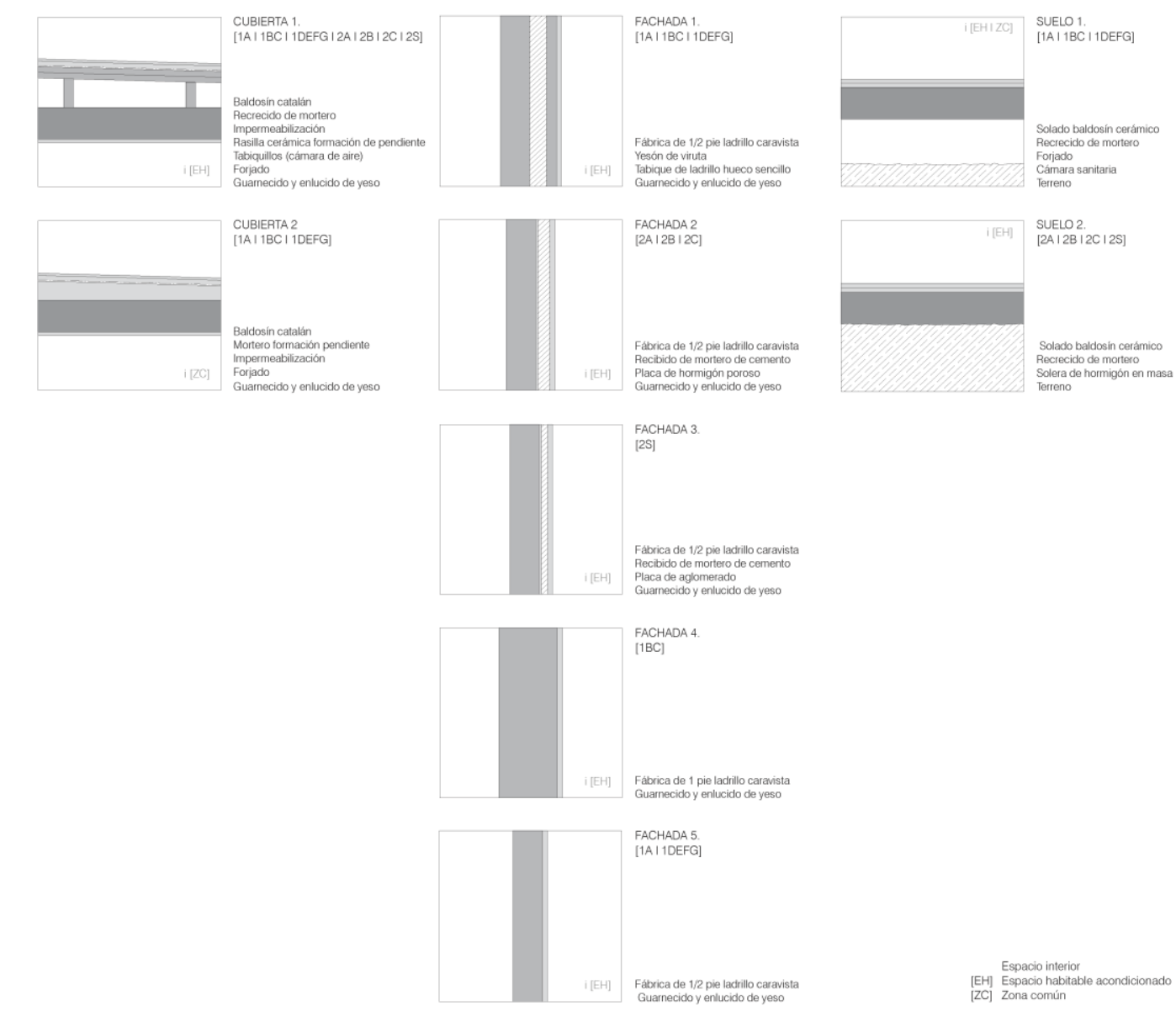

Fuente: Elaboración propia.

La transmitancia que presenta la cubierta 1, mayoritaria en una proporción del 99,8\% de la superficie total, y situada sobre espacios interiores habitables, es $U=1,94 \mathrm{~W} / \mathrm{m}^{2} \mathrm{~K}$, coeficiente que supera los estándares mínimos actuales en 3,85 veces ${ }^{22}$ debido a su falta de aislamiento, lo que provoca un alto riesgo de condensaciones superficiales (Figura 5).

${ }^{21}$ Se consulta el Informe del estado del Poblado Dirigido de Caño Roto de Aroca Asociados y Euroconsult, 1992 (Archivo particular CREA arquitectos, Madrid. Sin signatura) y el Informe y valoración: rehabilitación privada del Poblado de Absorción y Dirigido de Caño Roto de la Consejería de Política Territorial de la Comunidad de Madrid, 1994 (Centro de documentación especializada de la Consejería de Medio Ambiente y Ordenación del Territorio de la Comunidad de Madrid. Signatura: E FG 25 ARQ 94068).

${ }^{22}$ El valor límite para la zona climática D es de $0,40 \mathrm{~W} / \mathrm{m} 2 \mathrm{~K}$, según el Apartado 2.2.1.2., tabla 2.3, del DB-HE 1 .

ACE, 14 (42) CC BY-ND 3.0 ES | UPC Barcelona, España | La envolvente en la rehabilitación de conjuntos de vivienda 
Figura 5. Estado Inicial. Comparativa de soluciones de cubierta, fachada y suelo en función de su transmitancia térmica $\left[\mathrm{U}\left(\mathrm{W} / \mathrm{m}^{2} \mathrm{~K}\right)\right]$ y porcentaje respecto al total de superficie intervenida [\%]
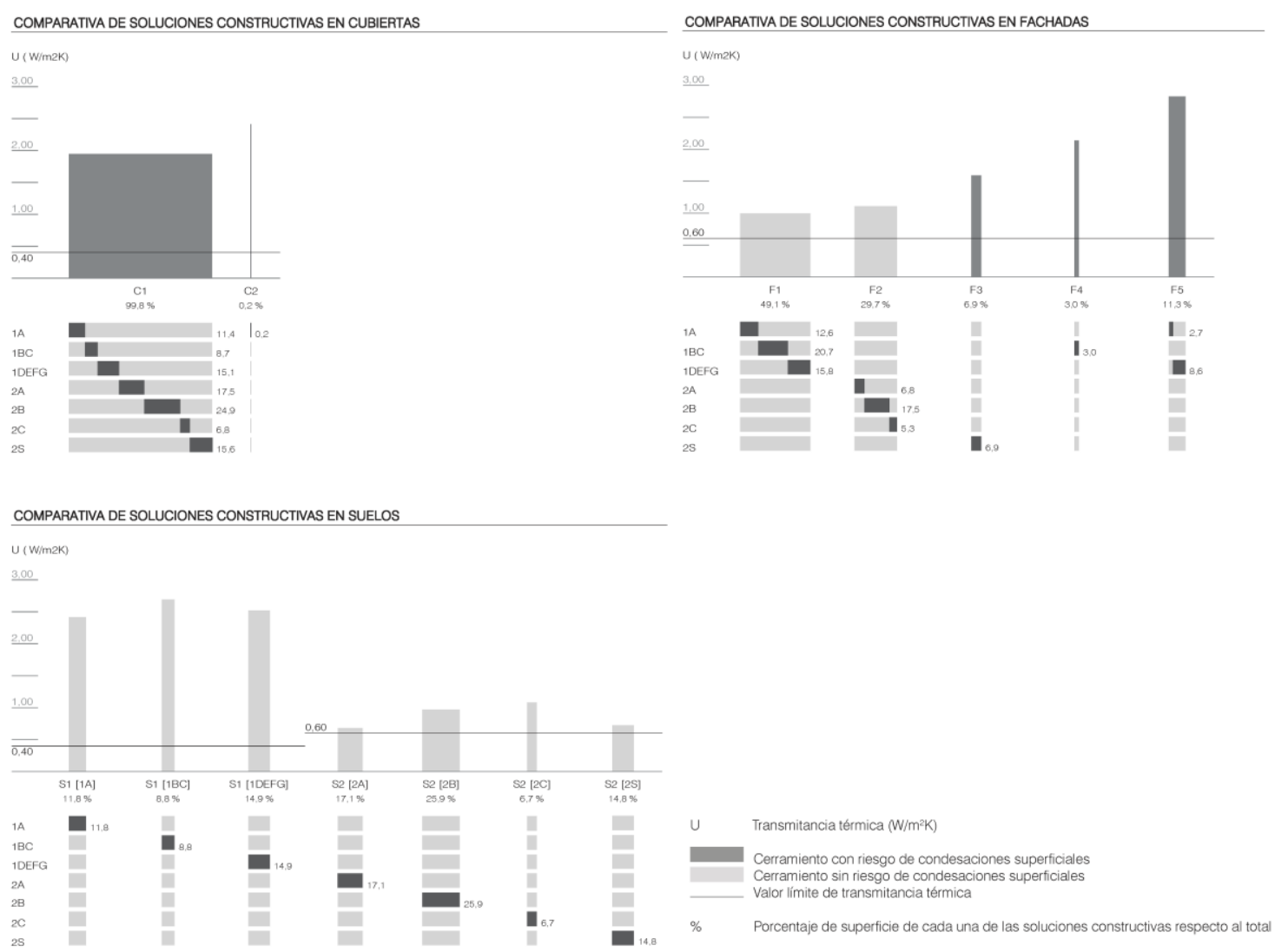

Fuente: Elaboración propia.

El encuentro con la fachada se realiza, en el caso de los bloques, con la estructura horizontal enrasada a la cara exterior y en las viviendas unifamiliares, con la hoja exterior de la fachada pasante por delante del forjado, presentando en ambos casos riesgo de condensación superficial en los puentes térmicos (Figura 6).

Estado de conservación:

- Falta de estanqueidad que causa filtraciones y humedades.

- Falta de aislamiento que provoca humedades de condensación superficial y en puentes térmicos.

- Degradación de los petos de remate de la edificación en altura, que presentan importantes disgregaciones locales, roturas y vuelcos parciales, encontrándose en mal estado entre un 15 y un $20 \%$ de los mismos.

\subsection{Fachadas}

Los cerramientos, tanto de la edificación en altura como de las viviendas unifamiliares se resuelven de forma experimental con ladrillo silicocalcáreo visto, material de mayor masa y formato que el ladrillo cerámico, que aporta un color amarillento pálido a la edificación. En la edificación en altura, las fachadas tienen una hoja exterior de fábrica de medio pie de ladrillo, yesón de viruta e.=0,07 m. y tabique de ladrillo hueco sencillo guarnecido y enlucido al interior (fachada 1, e.=0,25 m.). La

ACE, 14 (42) CC BY-ND 3.0 ES | UPC Barcelona, España | La envolvente en la rehabilitación de conjuntos de vivienda protegida . DOI: http://dx.doi.org/10.5821/ace.14.42.8960 
separación con los espacios comunes exteriores se realiza en la torre 1BC, combinando este tipo de fachada con muros de carga de un pie de ladrillo guarnecido y enlucido (fachada 4, e.=0,26 m.), y en los bloques 1A y 1DEFG, con una hoja de medio pie de ladrillo guarnecido y enlucido (fachada 5, e.=0,14 m.). Con el paso del tiempo, estos núcleos pierden su carácter inicial de espacios exteriores, debido a que las Comunidades de Propietarios los cierran buscando una mayor protección. Los cerramientos de las viviendas unifamiliares, en los tipos 2A, 2B y 2C, están compuestos por una hoja de medio pie de ladrillo trasdosado con placa de hormigón poroso e.=0,05 $\mathrm{m}$. recibida con mortero de cemento y guarnecida y enlucida al interior (fachada 2, e.=0,20 m.) y en las del tipo 2S, la hoja exterior se trasdosa con placa de aglomerado "Vitroterm" e.=0,025 m. recibido con mortero de cemento, y guarnecido y enlucido (fachada 3, e.=0,18 m.) (Figura 4).

El tipo de fachada predominante en la edificación en altura es la fachada 1, en una proporción de un $49,1 \%$ respecto al total, que con una transmitancia $U=0,99 \mathrm{~W} / \mathrm{m}^{2} \mathrm{~K}$, supera en 0,65 veces los valores límite exigidos en la actualidad ${ }^{23}$. Este tipo edificatorio se complementa con las fachadas 4 y 5 , con presencia en un 3,0 y un $11,3 \%$ del total, cuyas transmitancias $U=2,14 \mathrm{~W} / \mathrm{m}^{2} \mathrm{~K}$ y $\mathrm{U}=2,83$ $\mathrm{W} / \mathrm{m}^{2} \mathrm{~K}$, que superan los valores límite en 2,56 y 3,71 veces, y su alto riesgo de condensación, constituyen puntos críticos en la envolvente. En las viviendas unifamiliares prevalece la fachada 2, con un $29,7 \%$ del total, que con una transmitancia $U=1,11 \mathrm{~W} / \mathrm{m}^{2} \mathrm{~K}$, supera en 0,85 veces los baremos actuales. La fachada 3 , en una proporción del 6,9\%, tiene una transmitancia $U=1,59 \mathrm{~W} / \mathrm{m}^{2} \mathrm{~K}$, que muestra la gran fragilidad del tipo 2S, con una diferencia de 1,65 veces respecto al límite actual y riesgo de condensación (Figura 5).

En cuanto a los encuentros de la fachada con la estructura, en la edificación en altura, los paños de cerramiento, vistos al exterior, quedan encintados por ella, en una solución que en la época se considera de gran modernidad (Figura 2). Supone sin embargo importantes puentes térmicos con riesgo de condensación, en el encuentro de las fachadas 1, 4 y 5 con los pilares y con los forjados. En las viviendas unifamiliares, la hoja exterior de las fachadas 2 y 3 pasa por delante del forjado, existiendo en el segundo caso, por la fragilidad de la fachada, riesgo de condensación en el puente térmico (Figura 6).

También en los encuentros de la fachada con los huecos existe riesgo de condensación, constituyendo los puntos más críticos aquellos dinteles en los que se añade caja de persiana. En proyecto, la mayor parte de los huecos está compuesta por carpintería metálica y vidrio simple. Como casos excepcionales, hay que citar los huecos del tipo 1DEFG hacia el corredor de acceso y los situados en la planta baja de las viviendas unifamiliares hacia el patio, ambos de madera y vidrio simple, y los huecos de acceso a todas las viviendas, con marco y hoja de madera. La transmitancia de los huecos acristalados presenta valores muy elevados, con $\mathrm{UH}=5,70 \mathrm{~W} / \mathrm{m}^{2} \mathrm{~K}$ cuando existe carpintería metálica y de hasta $U \mathrm{H}=5,05 \mathrm{~W} / \mathrm{m}^{2} \mathrm{~K}$ con carpintería de madera, que superan entre 1,11 y 0,87 veces los valores máximos observados en la actualidad ${ }^{24}$.

Los cambios introducidos en los huecos por los usuarios, a pesar de alterar sustancialmente el criterio compositivo de las fachadas (Figura 2), mejoran ligeramente estos valores iniciales. Considerando sus nuevas dimensiones y unas características unificadas de las carpinterías con marco metálico sin rotura de puente térmico y vidrios 4+6+4 $\mathrm{mm}$., la nueva transmitancia de los huecos se sitúa entre $U_{H}=3,56 \mathrm{~W} / \mathrm{m}^{2} \mathrm{~K}$ y $U_{H}=4,44 \mathrm{~W} / \mathrm{m}^{2} \mathrm{~K}$, superando entre 0,32 y 0,64 veces los valores requeridos en la actualidad.

\footnotetext{
${ }^{23}$ El valor límite para la zona climática D es de 0,60 W/m2K, según el Apartado 2.2.1.2., tabla 2.3, del DB-HE 1 .

${ }^{24}$ El valor límite para la zona climática D es de 2,70 W/m2K, según el Apartado 2.2.1.2., tabla 2.3, del DB-HE 1.
}

ACE, 14 (42) CC BY-ND 3.0 ES | UPC Barcelona, España | La envolvente en la rehabilitación de conjuntos de vivienda 
Estado de conservación.

- Falta de estabilidad de los paños de fachada por escasez de fijación a la estructura, que afecta aproximadamente a un $60 \%$ de la superficie. Como principales causas, se encuentran los ciclos de dilatación térmica, la degradación ambiental del material, el efecto de los anclajes de instalaciones urbanas y la acción de los agentes del entorno. Puede causar desplazamientos del plano de cerramiento, desplomes puntuales y un potencial riesgo de desprendimiento.

- Falta de estanqueidad con humedades por filtraciones.

- Insuficiente aislamiento térmico y acústico.

- Alteración del estado de proyecto por actuaciones individuales de los vecinos. Se trata de modificaciones descoordinadas, en las que se cambian los tamaños de los huecos y se cierran terrazas, restando resistencia a la fábrica y provocando una alteración de la composición de las fachadas. Afecta aproximadamente a un 70\% de los huecos, al cerramiento de las zonas comunes de la edificación en altura, que pasan a ser interiores, y a edificaciones complementarias en los patios de las viviendas unifamiliares.

\subsection{Suelos}

En los edificios en altura, el encuentro de las viviendas con el terreno se produce mediante un forjado con solado de baldosín sobre cámara de aire, con la que se absorben las diferencias de cota del terreno, y que, en función de su altura libre, puede acoger un sótano o locales comerciales abiertos al exterior (suelo 1, e. $=0,17 \mathrm{~m}$.).

En las viviendas unifamiliares, el nivel habitable se establece a cota de calle mediante solera con solado de baldosín sobre lecho de cenizas, escorias o grava (suelo 2, e.= 0,17 m.) (Figura 4). La transmitancia que presentan ambas soluciones constructivas en las distintas tipologías depende de las características geométricas de los mismos. El suelo 1, que supone un 35,5\% del total, oscila entre $\mathrm{U}=2,41 \mathrm{~W} / \mathrm{m}^{2} \mathrm{~K}$ en el tipo $1 \mathrm{~A}$ y $\mathrm{U}=2,61 \mathrm{~W} / \mathrm{m}^{2} \mathrm{~K}$ en el $1 \mathrm{BC}$, con una diferencia de 5,02 y 5,52 veces respecto a los valores admisibles en la actualidad ${ }^{25}$, debido a la falta de aislamiento y ventilación.

El suelo 2, en el 64,5\% restante, con transmitancias entre $U=0,68 \mathrm{~W} / \mathrm{m}^{2} \mathrm{~K}$ en el tipo $2 \mathrm{~A}$ y $\mathrm{U}=1,08$ $\mathrm{W} / \mathrm{m}^{2} \mathrm{~K}$ en el $2 \mathrm{C}$, se sitúa más próximo al límite actual, suponiendo una diferencia respecto a ellos de 0,13 y 0,80 veces $^{26}$ (Figura 5). Las características de ambas soluciones provocan que, independientemente de su situación y condiciones específicas, exista riesgo de condensación en el encuentro con la fachada (Figura 6).

Estado de conservación.

- Falta de estanqueidad con humedades y condensaciones debidas a: las frecuentes roturas en los conductos de saneamiento y acometida; el estado de los sótanos y cámaras situados bajo el forjado, en general no saneados ni ventilados y con acumulaciones de tierras y escombro; la existencia de jardines rodeando los edificios; y la elevada cota del nivel freático.

\footnotetext{
${ }^{25}$ El valor límite para la zona climática $D$ es de $0,40 \mathrm{~W} / \mathrm{m} 2 \mathrm{~K}$, según el Apartado 2.2.1.2., tabla 2.3, del $D B-H E 1$.

${ }^{26}$ El valor límite para la zona climática $\mathrm{D}$ es de 0,60 W/m2K, según el Apartado 2.2.1.2., tabla 2.3, del DB-HE 1.
}

ACE, 14 (42) CC BY-ND 3.0 ES | UPC Barcelona, España | La envolvente en la rehabilitación de conjuntos de vivienda protegida . DOI: http://dx.doi.org/10.5821/ace.14.42.8960 

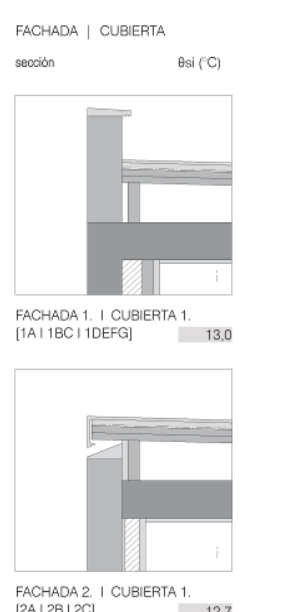

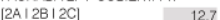

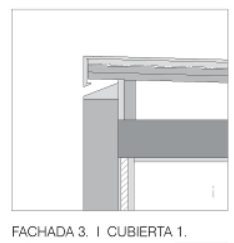

FACHADA 3. I CUBIERTA 1.
[2S]

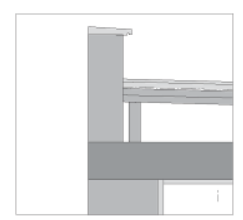

FACHADA 4. I CUBIERTA 1.
$[1 \mathrm{BC}]$

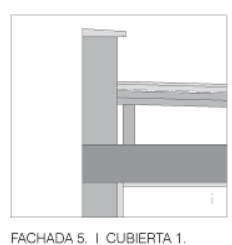

FACHADA 5. I CUBIERTA 1.
[1A]

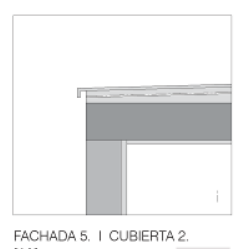

FACHADA 5. I CUBIERTA2.
[1A]
Figura 6. Estado inicial. Estudio de puentes térmicos

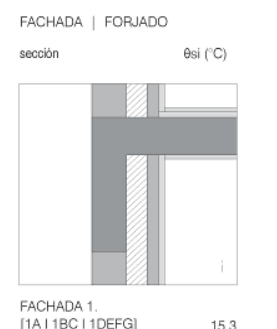

$[1 \mathrm{~A}|1 \mathrm{BC}| 1 \mathrm{DEFG}]-15$

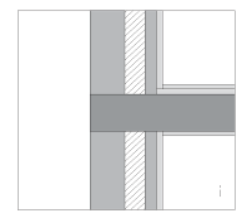

FACHADA 1 .
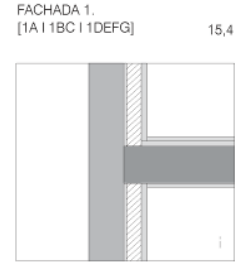

FACHADA 2.
[2A I 2B। $2 \mathrm{C}]$

FACHADA | PILAR

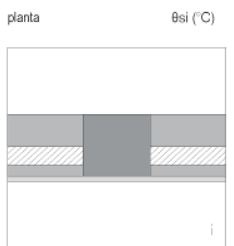

FACHADA 1.
[1AI IBC I 1 DEFG]

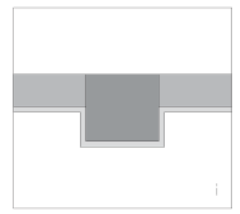

FACHADA 5.
[1DEFG]

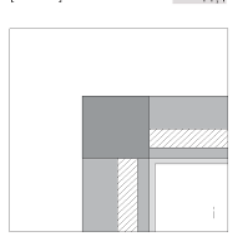

\begin{tabular}{l} 
FACHADA 1. \\
[1A| 1BC I 1DEFG] \\
\hline
\end{tabular}

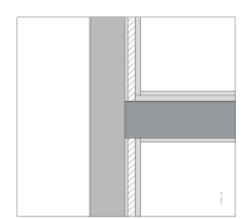

FACHADA 3.

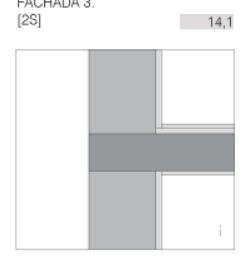

FACHADA 4

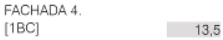

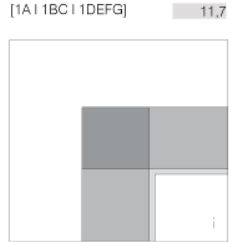

FACHADA 4.

$[1 \mathrm{BC}]$

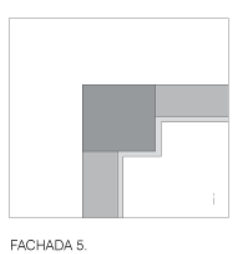

FACHADA 5.
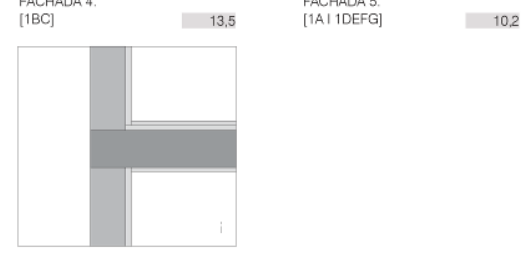

FACHADA 5

12,2

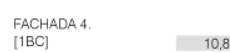

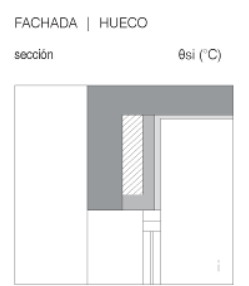

FACHADA 1.
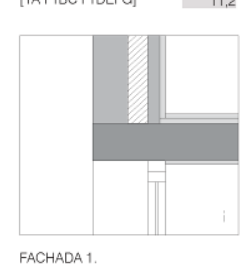

FACHADA 1.
[1BC]
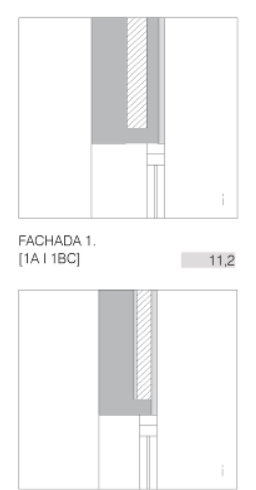

FACHADA2.
[2A|2B।2C]

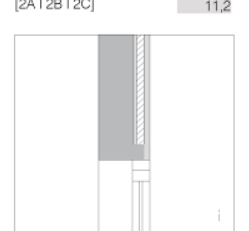

FACHADA 3
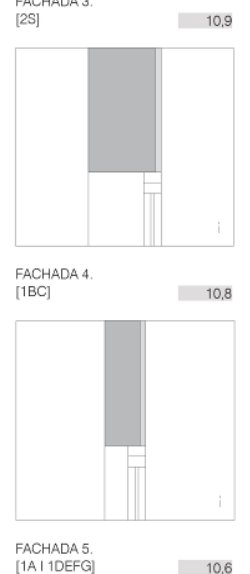

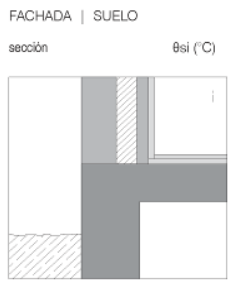

FACHADA 1, I SUELO 1.
[1AI IBCI IDEFG]

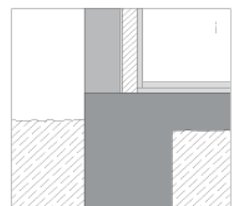

FACHADA2. I SUELO 2

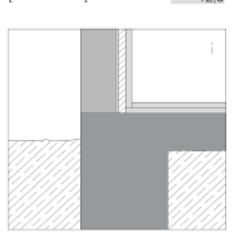

FACHADA 3. I SUELO 2.

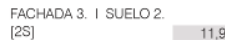

Modificación genérica
FACHADA | HUECO

Cambio de carpintería con caja

de persiana muy ventliada sir
aislamiento

$\theta$ si Temperatura mínima en la superficie interior del cerramiento $\left({ }^{\circ} \mathrm{C}\right)$

No cumple con la limitación de condesaciones superficiales del CTE*

*Se estima que con las condiciones clímaticas propias de la ubicación de las edificaciones objeto del estudio hay riesgo decondesaciones superficiales, si $\theta$ si $<14,6^{\circ} \mathrm{C}$ Fuente: Elaboración propia.

ACE, 14 (42) CC BY-ND 3.0 ES | UPC Barcelona, España | La envolvente en la rehabilitación de conjuntos de vivienda 


\subsection{Valoración higrotérmica y del estado de conservación de la envolvente}

En resumen, la envolvente térmica de la edificación presenta importantes deficiencias, tanto por sus características constructivas como por su estado de conservación, destacando:

- Altas transmitancias en cubiertas, suelos y fachadas, principalmente en aquellas de los bloques que sirven de separación con los elementos comunes de carácter exterior, y en las viviendas unifamiliares tipo $2 \mathrm{~S}$.

- Puentes térmicos en prácticamente todos los encuentros, destacando los de la fachada con la estructura y las carpinterías, que se acentúan cuando existe cajón de persiana sin aislamiento.

- Falta de estabilidad y de estanqueidad de la fachada.

- Mal comportamiento de las soleras y forjados sanitarios, con condensaciones y humedades.

\section{Estado modificado de la envolvente}

La intervención se realiza tomando como referencia la Norma Básica de la Edificación NBE-CT-79 Condiciones térmicas de los Edificios, como se precisa en los Proyectos de Rehabilitación de la edificación en altura y viviendas unifamiliares ${ }^{27}$ del poblado (Figura 3).

\subsection{Cubiertas}

Las cubiertas se someten a una total renovación con la que se busca garantizar su estanqueidad, mediante sistemas que reduzcan al máximo la producción de desechos de obra y garanticen el correcto drenaje en mínimas condiciones de mantenimiento. Se hace necesario para ello la previa reparación de las cubiertas existentes, o su demolición si así se considera oportuno, y su encuentro con el peto. En los bloques $1 \mathrm{~A}$ se forma una cubierta invertida sobre la existente, plana ventilada en vivienda y no ventilada en zonas comunes, que se compone de: acabado de protección de grava, aislamiento con placas rígidas de poliestireno extruido e.=0,04 m., impermeabilización con doble lámina, geotextil y nueva formación de pendientes de hormigón aligerado (cubiertas 1.R1, e.=0,54 m., y 2.R1, e.=0,45 m.).

En las torres 1BC y los bloques 1DEFG se construye una sobrecubierta ligera y de distinta pendiente que la cubierta plana ventilada existente, con cubrición de paneles sándwich de chapa plegada galvanizada prelacada y aislamiento interior de poliuretano o similar e.=0,03 m., anclados a un entramado de soporte formado por perfilería de chapa galvanizada preconformada en frío (cubierta 1.R2, e.= 0,03+CA+0,35 m.). Esta solución es continua sobre los espacios comunes de la torre 1BC de cubierta plana no ventilada (cubierta 2.R2, e.= 0,03+CA+0,25 m.), resolviéndose en los del bloque 1DEFG con acabado de grava (cubierta 2.R1). En estos dos tipos, se añade un volumen para el ascensor, que tiene cubierta plana formada por: panel sándwich de chapa plegada galvanizada prelacada y aislamiento interior de poliuretano o similar e.=0,03 m., sobre cámara de aire de 0,10 m. y forjado de chapa colaborante (cubierta 3, e.= 0,21 m.). En las viviendas unifamiliares, se construye una nueva cubierta sobre la existente plana ventilada, formada por: acabado de protección de grava sobre dos capas de espuma de poliuretano e.=0,03 m., la superior de gran densidad y resistencia mecánica (cubierta 1.R3, e.= 0,45 m.) (Figura 7).

\footnotetext{
27 Se consultan los Proyectos de Ejecución para la Rehabilitación de cada una de las tipologías edificatorias, elaborados por E. Hernández Fernández, J. L. López Delgado y G. Ruiz Palomeque, 1994-2001 (Archivo particular CREA arquitectos, Madrid).
} 
Figura 7. Estado modificado. Soluciones constructivas de cubierta, fachada y suelo

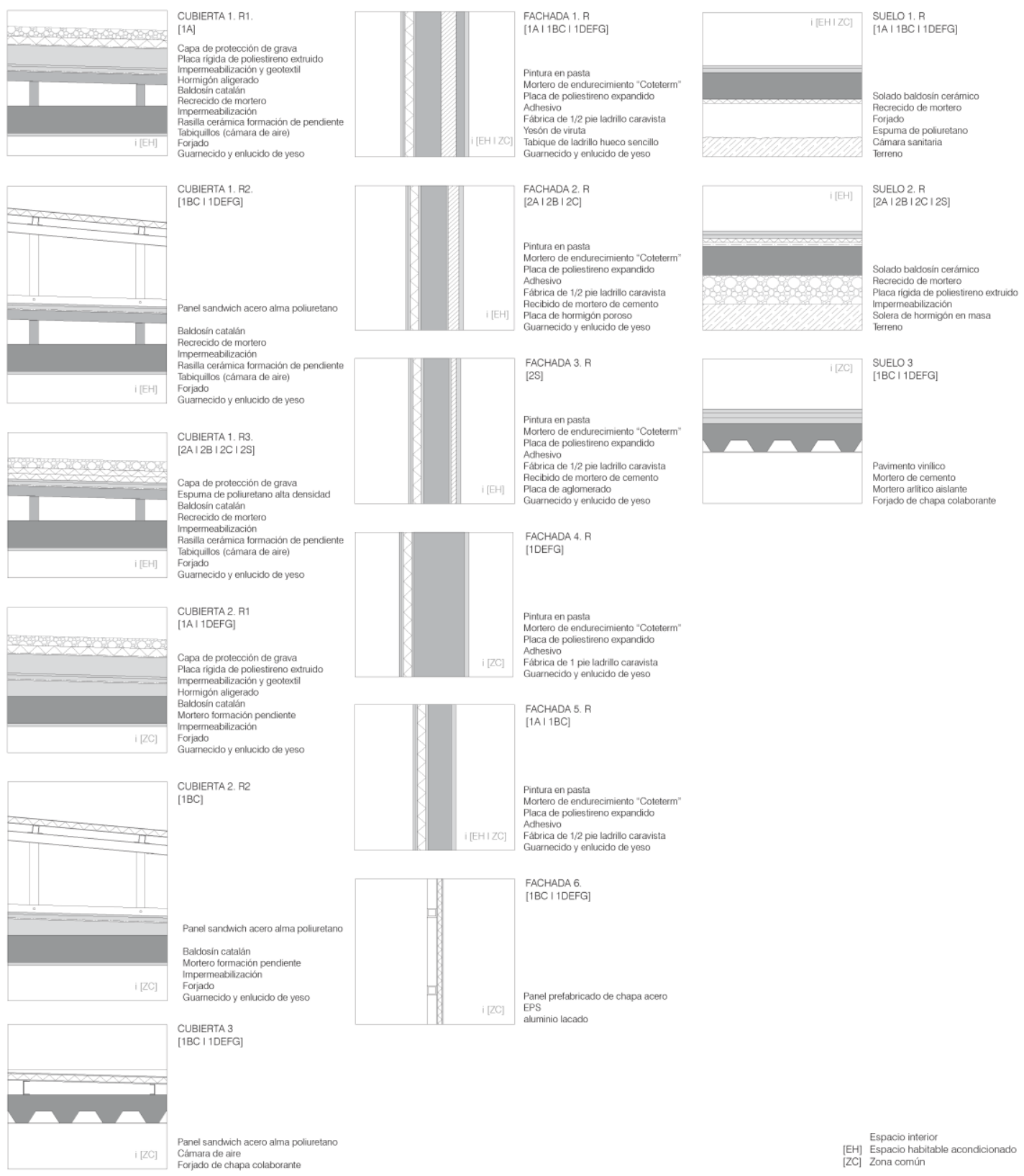

Fuente: Elaboración propia.

En la edificación en altura, la cubierta 1.R1, en un porcentaje del 11,1\% de la superficie que plantea la rehabilitación, presenta buenas condiciones de aislamiento, con un valor de transmitancia $U=0,56$ $\mathrm{W} / \mathrm{m}^{2} \mathrm{~K}$, ligeramente superior a los valores permitidos en la actualidad ${ }^{28}$. Su comportamiento es mucho mejor que el de la cubierta 1.R2, presente en un 22,9\%, que con $U=1,02 \mathrm{~W} / \mathrm{m}^{2} \mathrm{~K}$ supera en 1,55 veces el baremo actual.

${ }^{28}$ El valor límite para la zona climática $D$ es de 0,40 W/m2K, según el Apartado 2.2.1.2., tabla 2.3, del DB-HE 1.

ACE, 14 (42) CC BY-ND 3.0 ES | UPC Barcelona, España | La envolvente en la rehabilitación de conjuntos de vivienda 
Sobre las zonas comunes, las cubiertas 2.R1 y 2.R2, tienen unas transmitancias $U=0,60 \mathrm{~W} / \mathrm{m}^{2} \mathrm{~K}$ y $\mathrm{U}=1,24 \mathrm{~W} / \mathrm{m}^{2} \mathrm{~K}$, valores que superan al máximo actual en 0,5 y 2,10 veces, y sobre los volúmenes añadidos para contener ascensores y accesos, la cubierta 3, con $\mathrm{U}=0,79 \mathrm{~W} / \mathrm{m}^{2} \mathrm{~K}$, lo supera en 0,97 veces. En las viviendas unifamiliares, la cubierta 1.R3, propuesta en proyecto en una proporción del $61,1 \%$ de la superficie que plantea la rehabilitación, tiene un comportamiento equivalente al exigido en la actualidad con una transmitancia $\mathrm{U}=0,42 \mathrm{~W} / \mathrm{m}^{2} \mathrm{~K}$ (Figura 8).

Los encuentros en todos los tipos de cubierta se producen con el aislamiento pasante por el frente de fachada, forjado y peto, lo que asegura una buena solución del puente térmico, eliminando el riesgo de condensación interior (Figura 9). Las cubiertas 1.R1 y 1.R2, en los bloques 1A y 1DEFG, se resuelven con viga de coronación sobre el forjado y la cubierta 1.R2, en las torres 1BC, se forma con la sustitución del peto existente por uno nuevo de medio pie de ladrillo, sobre un perfil UPN-120 de atado de las vigas de cubierta.

Estado de conservación:

- No constan problemas de estanqueidad o aislamiento.

- No consta ningún tipo de degradación de los acabados u obstrucciones en los elementos de desagüe, ni mal estado de los elementos añadidos, que son eliminados y repuestos.

\subsection{Fachadas}

Las fachadas se protegen con un sistema de revestimiento tipo "Coteterm", compuesto por placas de poliestireno expandido e.=0,04 m., en los recercados de los huecos e.=0,02 m., y acabado de mortero acrílico armado con fibra de vidrio, fijado al soporte de forma mecánica. En la edificación en altura, la inestabilidad generalizada de los paños de fachada hace necesaria una previa consolidación de los mismos, mediante la fijación de las superficies que presentan desplomes o pérdidas de planeidad, y la demolición y reconstrucción de las manifiestamente inestables. En los cerramientos de las viviendas, el revestimiento de "Coteterm" se aplica sobre fachada de doble hoja (fachada 1.R, e.= 0,32 m.), y en las zonas comunes, se incorpora al de una hoja de un pie, en el bloque 1DEFG, (fachada 4.R, e.= 0,33 m.) y al de una hoja de medio pie, en los bloques $1 \mathrm{~A}$ y $1 \mathrm{BC}$, (fachada 5.R, e. $=0,21 \mathrm{~m}$.).

Los volúmenes añadidos a las zonas comunes de los bloques 1BC y 1DEFG para contener ascensores y accesos, se forman con panel prefabricado de chapa de acero y EPS (fachada 6, e.= 0,02 m.). En las viviendas unifamiliares, en los tipos 2A, 2B y 2C, el revestimiento tipo "Coteterm" se superpone a una fachada de una hoja trasdosada de placa de hormigón poroso (fachada 2.R, e.= 0,27 m.) y en el tipo 2S, a una fachada de una hoja trasdosada de placa de aglomerado tipo "Vitroterm" (fachada 3.R, e.= 0,24 m.) (Figura 7).

La fachada predominante en el conjunto, presente en la edificación en altura es la fachada F1.R, con un porcentaje del 53,00\% de la superficie que plantea la rehabilitación, tiene una transmitancia $\mathrm{U}=0,47 \mathrm{~W} / \mathrm{m}^{2} \mathrm{~K}$. Acompañada de las fachadas propuestas para las viviendas unifamiliares, F2.R en un $32,50 \%$, con $U=0,50 \mathrm{~W} / \mathrm{m}^{2} \mathrm{~K}$, y F3.R en un $7,40 \%$, con $\mathrm{U}=0,57 \mathrm{~W} / \mathrm{m}^{2} \mathrm{~K}$, presentan unos valores que cumplen los baremos actuales ${ }^{29}$.

Los cerramientos de los espacios comunes de las viviendas colectivas, los incrementan mínimamente en las fachadas 4.R y $5 . R$, que tienen valores $U=0,63 \mathrm{~W} / \mathrm{m}^{2} \mathrm{~K}$ y $U=0,68 \mathrm{~W} / \mathrm{m}^{2} \mathrm{~K}$ respectivamente, y con un mayor margen en el cerramiento de los volúmenes añadidos, que alcanzan una transmitancia $\mathrm{U}=1,46 \mathrm{~W} / \mathrm{m}^{2} \mathrm{~K}$, superándolos en 1,43 veces (Figura 8).

${ }^{29}$ El valor límite para la zona climática D es de 0,60 W/m2K, según el Apartado 2.2.1.2., tabla 2.3, del DB-HE 1.

ACE, 14 (42) CC BY-ND 3.0 ES | UPC Barcelona, España | La envolvente en la rehabilitación de conjuntos de vivienda 
Figura 8. Estado modificado. Comparativa de soluciones de cubierta, fachada y suelo en función de su transmitancia térmica $\left[\mathrm{U}\left(\mathrm{W} / \mathrm{m}^{2} \mathrm{~K}\right)\right]$ y porcentaje respecto al total de superficie intervenida [\%]
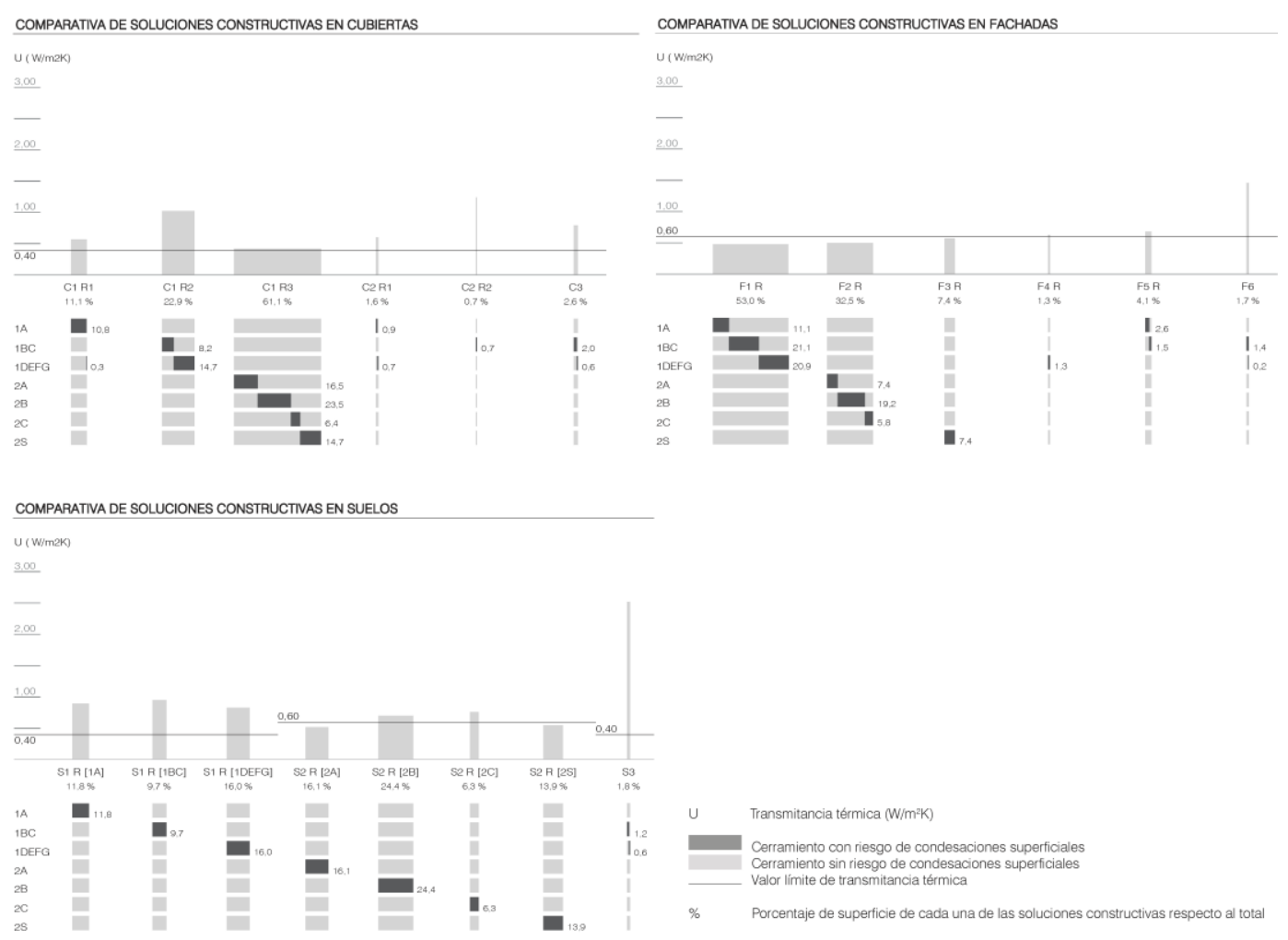

Fuente: Elaboración propia.

El hecho de que el "Coteterm" funcione como un revestimiento continuo por el exterior de la envolvente, soluciona los encuentros de la fachada con la estructura, eliminando los puentes térmicos (Figura 9). El punto más vulnerable son los huecos, en los que no se cambian ni duplican las carpinterías por decisión de los vecinos ${ }^{30}$, por haber sido modificadas de forma individual a lo largo de la vida de la edificación, como se ha descrito en el estado inicial.

Estado de conservación:

- No constan problemas de estabilidad, estanqueidad o aislamiento.

- Se toman medidas de unificación visual de las actuaciones individuales llevadas a cabo por los vecinos mediante la colocación de contraventanas de lamas de aluminio en los huecos y la sustitución de elementos añadidos por sistemas unificados de tenderos, protecciones visuales de las maquinarias exteriores de aire acondicionado, o canaletas para el cableado, con el objeto de aportar orden y unidad a las fachadas (Figura 3).

\subsection{Suelos}

En la edificación en altura, el forjado inferior, con solado de baldosín sobre recrecido de mortero, se aísla en su cara baja con poliuretano proyectado sobre cámara sanitaria de mínimo 1,20 m. de altura, o con placas de polydros fijadas y guarnecidas con yeso, sobre sótano o local comercial (suelo 1.R, e.= 0,19 m.).

\footnotetext{
30 En la Memoria de los Proyectos se expone que con la reducción de pérdidas que consigue el aislamiento de fachada, hace que no sea necesario el cambio de ventanas para alcanzar los mínimos de la NBE CT-97.
}

ACE, 14 (42) CC BY-ND 8.0 ES | UPC Barcelona, España | La envolvente en la rehabilitación de conjuntos de vivienda protegida . DOI: http://dx.doi.org/10.5821/ace.14.42.8960 
Figura 9. Estado modificado. Estudio de puentes térmicos
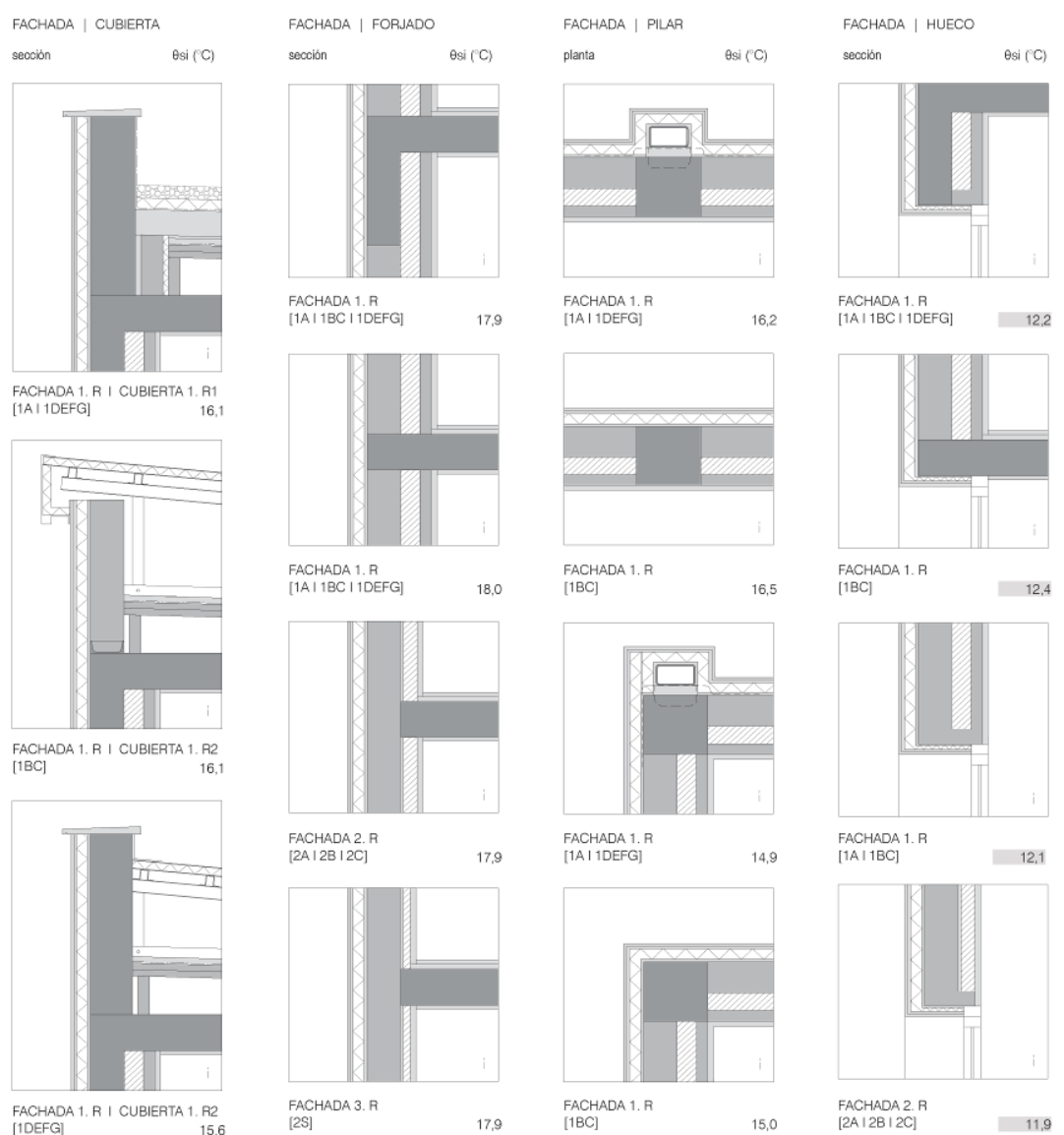

FACHADA $1 . \mathrm{R}$
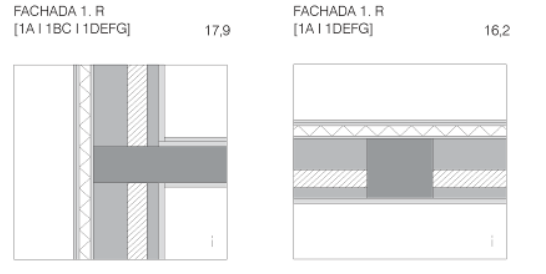

\begin{tabular}{l} 
FACHADA 1.R \\
[1A] 1BC I 1 1DEFG] \\
\hline
\end{tabular}

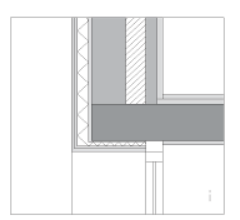

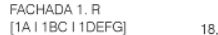

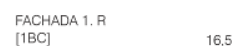

FACHADA 1
$[1 B C]$

FACHADA | CUBiERTA | SUELO

secoión $\quad$ esi (C)
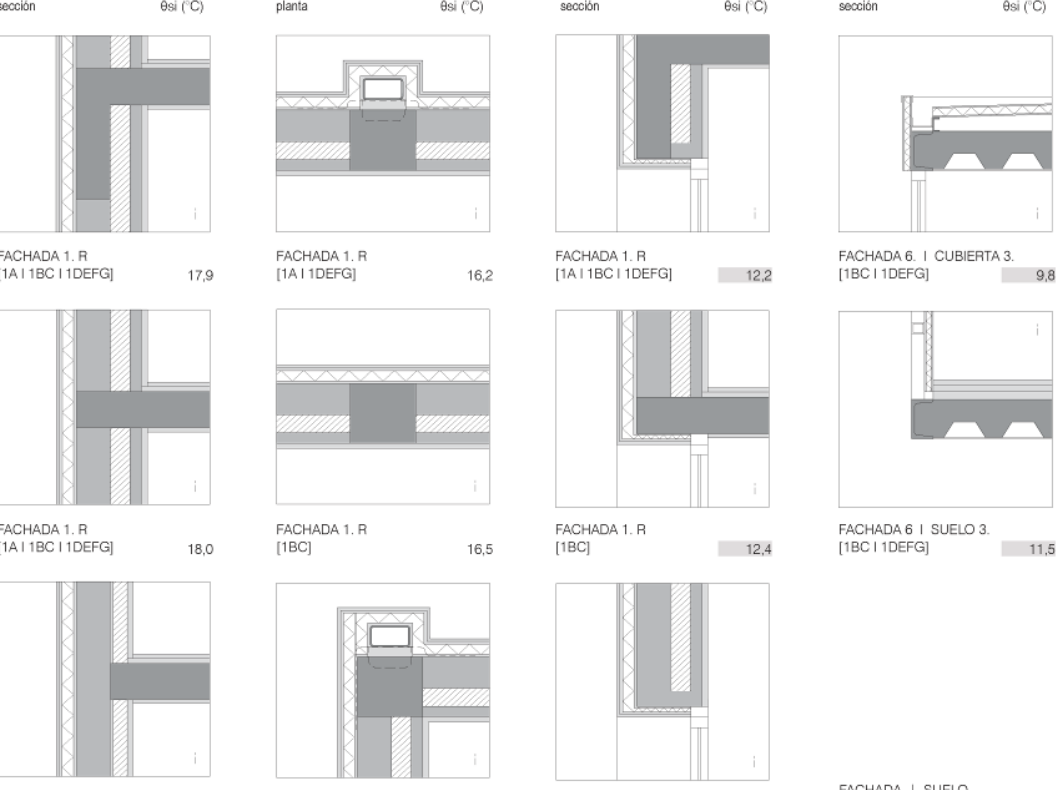

FACHADA 6. I CUBIERTA 3.

$[1 \mathrm{BC} / 1 \mathrm{DEFG}]$
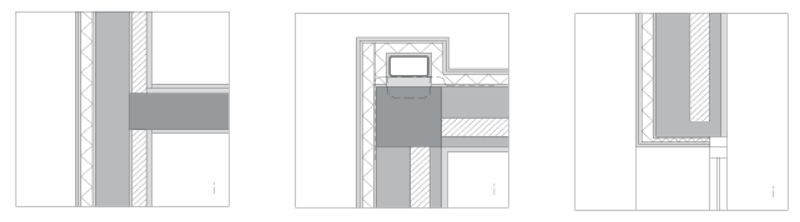

FACHADA 2.
$[2 \mathrm{~A}|2 \mathrm{~B}| 2 \mathrm{C}]$

17,9

FACHADA 1. R
[1A. IDEFG]

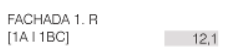

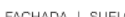
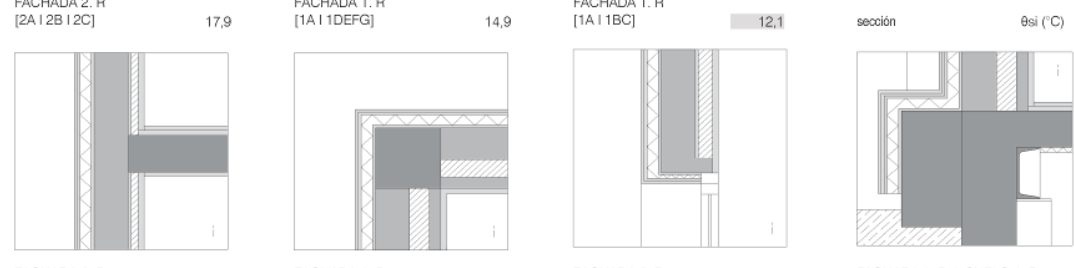

FACHADA 3. R
[2S]

FACH

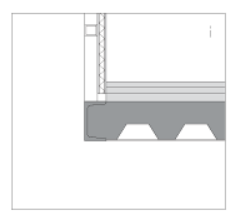

FACHADA 6 I SUELO 3.
$[1 B C$. 1DEFG]
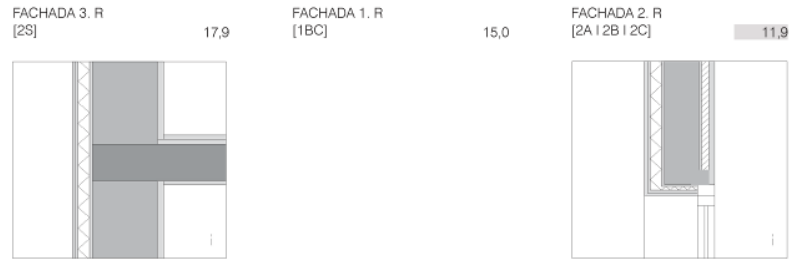

FACHADA 1. R I SUELO 1. R
$[1 A]$

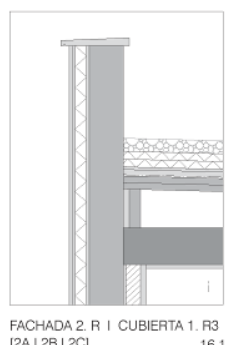

FACHADA 4. R
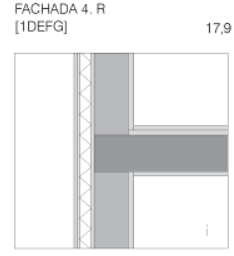

FACHADA 5. R
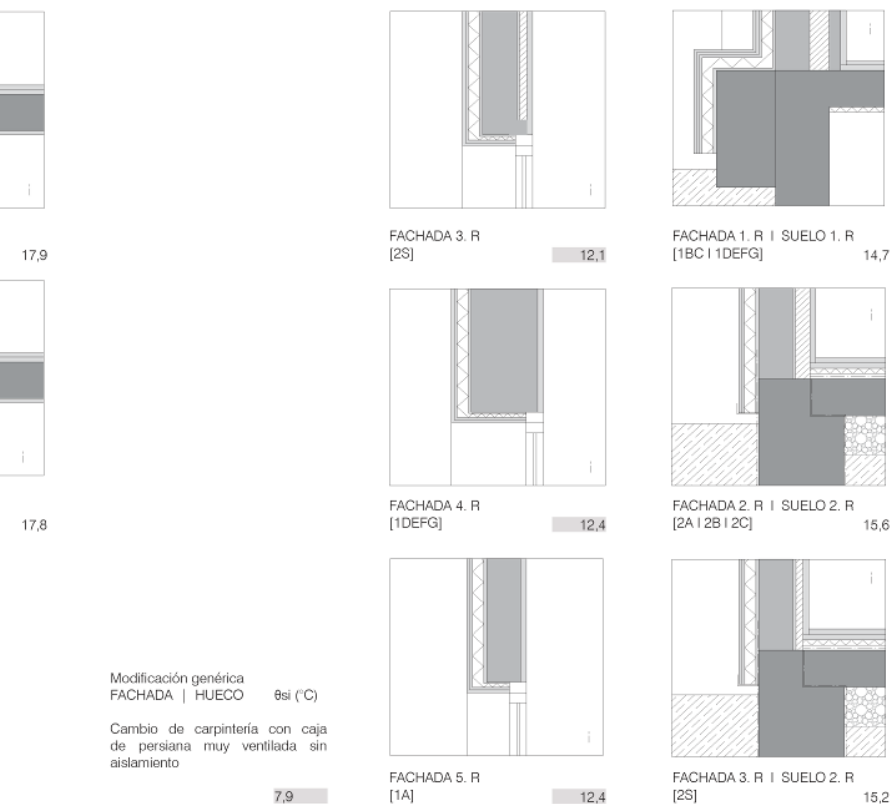

FACHADA 1. R I SUELO 1. R
[1BC I IDEFG]

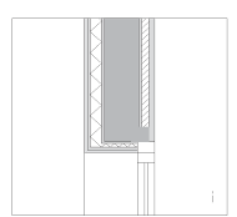

FACHADA 2.R I CUBIERTA 1. B3
[2A I2B I 2C]

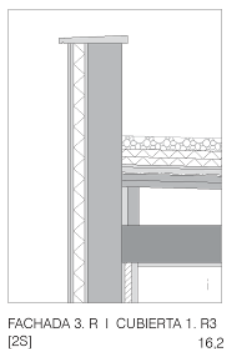

$\theta$ si Temperatura mínima en la superficie interior del cerramiento $\left({ }^{\circ} \mathrm{C}\right)$

79

Cambio de carpintería con caja
de persiana muy ventilada sin

$[1 A]$

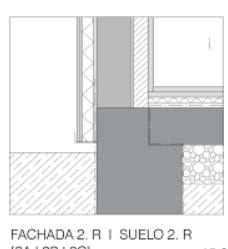

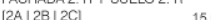

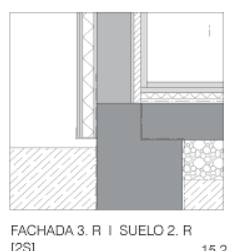

No cumple con la limitación de condesaciones superficiales del CTE*

*Se estima que con las condiciones clímaticas propias de la ubicación de las edificaciones objeto del estudio hay riesgo decondesaciones superficiales, si $\theta$ si $<14,6^{\circ} \mathrm{C}$ Fuente: Elaboración propia. 
En los bloques 1BC y 1DEFG, las pasarelas de los volúmenes añadidos con nuevos accesos y ascensores tienen forjado de chapa colaborante con pavimento vinílico sobre dos capas de mortero, de cemento y aislante (suelo 3, e.= 0,15 m.). En las viviendas unifamiliares con actuación funcional de nivel máximo, se rebaja el terreno situado bajo la solera para aplicar una imprimación con capa de oxiasfalto en el arranque de la cimentación y de los muros, y añadir un encachado drenante. Posteriormente se repone la solera con acabado de solado cerámico sobre recrecido de mortero, placa rígida de poliestireno extruido e.=0,02 m. y lámina de polietileno impermeabilizante (suelo 2.R, e.= 0,19 m.) (Figura 7).

En la edificación en altura, la transmitancia del suelo 1.R, en una proporción del 37,5\% de la superficie que plantea la rehabilitación, depende de las características geométricas del espacio al que sirve, oscilando entre $U=0,83 \mathrm{~W} / \mathrm{m}^{2} \mathrm{~K}$ y $\mathrm{U}=0,95 \mathrm{~W} / \mathrm{m}^{2} \mathrm{~K}$, con una diferencia de 1,07 y 1,37 veces respecto a los valores actuales ${ }^{31}$. En las viviendas unifamiliares, el suelo 2.R, propuesto como solución óptima para el $60,70 \%$ de los suelos, oscila entre $U=0,52 \mathrm{~W} / \mathrm{m}^{2} \mathrm{~K}$ en el tipo $2 \mathrm{~A}$ y $U=0,70$ $\mathrm{W} / \mathrm{m}^{2} \mathrm{~K}$, valores aproximados al máximo permitido por la norma actual ${ }^{32}$ (Figura 8). En el encuentro con la fachada se elimina el riesgo de condensación interior en puente térmico, tanto en el suelo 1.R, en el que se añade una viga de hormigón perimetral de atado, como en el suelo 2.R., presentando peor comportamiento el suelo 3, por su falta de aislamiento (Figura 9).

Estado de conservación:

- No constan problemas de estanqueidad o aislamiento en los bloques ni en las viviendas unifamiliares rehabilitadas.

\subsection{Valoración higrotérmica y del estado de conservación de la envolvente}

En resumen, la envolvente térmica presenta un buen comportamiento higrotérmico:

- Las transmitancias de los cerramientos alcanzan valores inferiores a los máximos permitidos por los baremos actuales, constituyendo los valores más elevados aquellos que delimitan las zonas comunes sin calefactar.

- No existe riesgo de condensaciones superficiales.

- No se detectan puentes térmicos en los encuentros entre la fachada y la cubierta, la estructura o el suelo, constituyendo el punto más débil, el encuentro con las carpinterías, único elemento en el que no se interviene.

\section{Resultados}

En el estado previo a la rehabilitación, la edificación manifiesta una situación crítica en la que las cubiertas y parte de las fachadas, principalmente las situadas en las viviendas unifamiliares tipo $2 S$ y en la separación con los espacios comunes exteriores de los bloques 1BC y 1DEFG, presentan: altas transmitancias, condensaciones superficiales, condensaciones en puentes térmicos, y falta de estanquidad. En los petos y fachadas es además frecuente una escasa estabilidad de la hoja exterior, y en los suelos se detectan condensaciones y problemas de humedades.

\footnotetext{
${ }^{31}$ El valor límite para la zona climática $D$ es de 0,40 W/m2K, según el Apartado 2.2.1.2., tabla 2.3, del $D B-H E 1$.

${ }^{32}$ El valor límite para la zona climática $\mathrm{D}$ es de $0,60 \mathrm{~W} / \mathrm{m} 2 \mathrm{~K}$, según el Apartado 2.2.1.2., tabla 2.3, del DB-HE 1.
} 
Tabla 1. Comparativa de la variación de transmitancia térmica $\left[\mathrm{U}\left(\mathrm{W} / \mathrm{m}^{2} \mathrm{~K}\right)\right]$ de cada cerramiento entre estado inicial y estado modificado

Estado inicial

Estado Modificado

\begin{tabular}{|c|c|c|c|}
\hline CUBIERTAS & $\mathrm{U}\left(\mathrm{W} / \mathrm{m}^{2} \mathrm{~K}\right)$ & & $\mathrm{U}\left(\mathrm{W} / \mathrm{m}^{2} \mathrm{~K}\right)$ \\
\hline \multicolumn{4}{|l|}{ Cubierta plana ventilada } \\
\hline \multirow[t]{3}{*}{ CUBIERTA 1. [1A | 1BC | 1DEFG | 2A | 2BC | 2S] } & 1,94 & CUBIERTA 1. R1 [1A | 1DEFG] & 0,56 \\
\hline & & CUBIERTA 1. R3 [2A | 2B | 2C I 2S] & 0,42 \\
\hline & & CUBIERTA 3 [1BC I 1DEFG] & 0,79 \\
\hline
\end{tabular}

Partición interior con espacio bajo cubierta

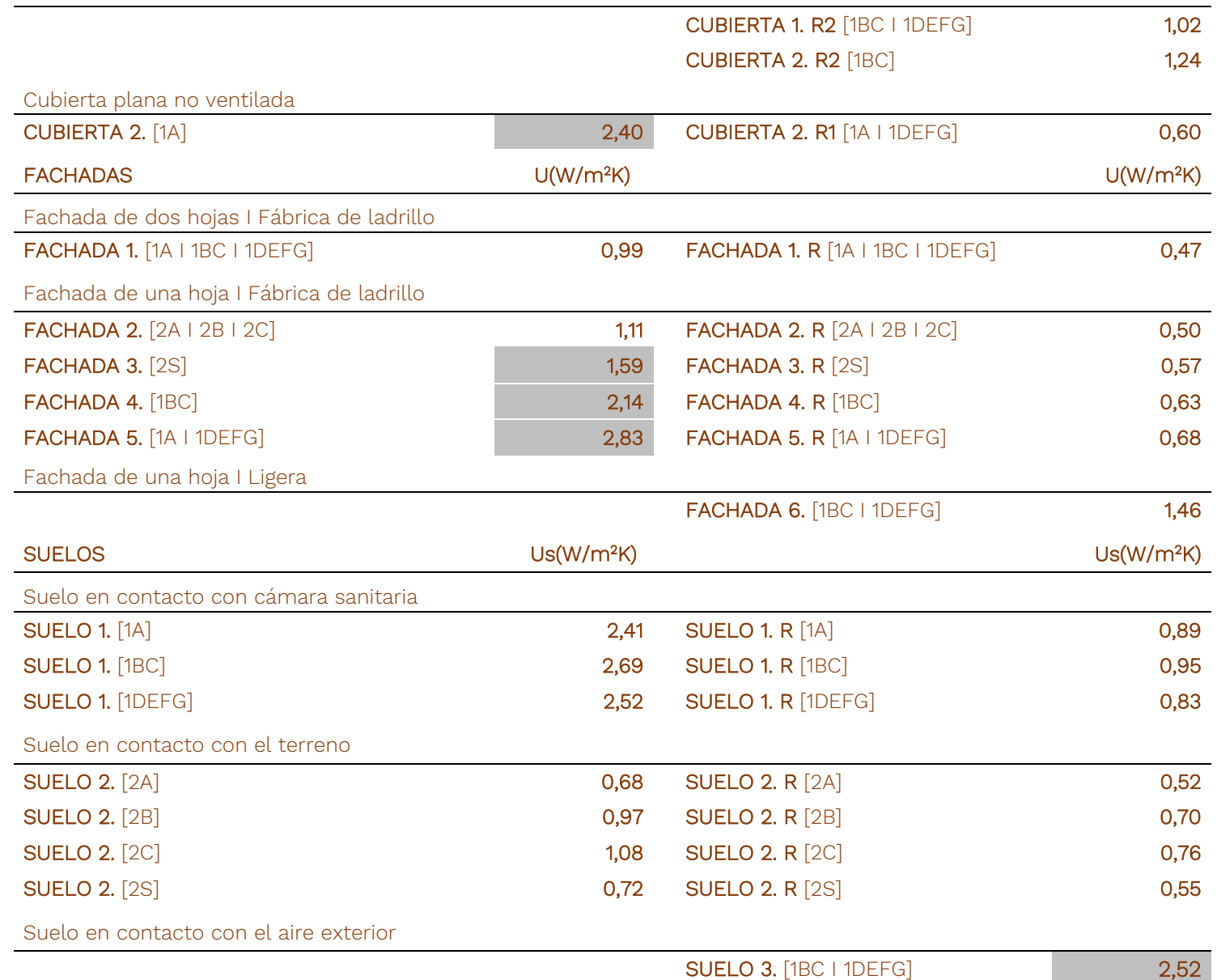

Nota: En gris cuando no cumple la limitación de condensaciones superficiales del CTE.

Fuente: Elaboración propia.

Estas patologías se solucionan con la fijación de la fábrica a la estructura y el trasdosado de aislamiento por el exterior. Se dota así a todos los elementos de unos valores de transmitancia que cumplen los baremos exigidos en la actualidad, se eliminan los puentes térmicos y se aporta estanqueidad a la envolvente. Como puntos más vulnerables, pueden citarse: el cerramiento de los espacios comunes en la edificación en altura y los huecos, en los que no se sustituyen o duplican carpinterías por cumplir con el resto de las medidas las condiciones térmicas de la edificación que dicta la Norma Básica de la Edificación NBE-CT-79, vigente durante la intervención. Las alteraciones de las fachadas producidas por actuaciones individuales de los vecinos se solucionan con un sistema unificado de contraventanas y protecciones visuales de elementos añadidos que, atendiendo a criterios prácticos, se superponen a los nuevos sistemas de acabado. 
Para tener una referencia sobre la eficiencia energética de la edificación del conjunto, se realiza el cálculo ${ }^{33}$ en un bloque representativo cuya situación presenta unas condiciones medias, el bloque 1DEFG ubicado en la avenida de Nuestra Señora de Valvanera n. 320 (figura 1). Se evalúa su comportamiento energético tras la construcción del poblado y en el momento previo a la intervención, incorporando los cambios en los huecos y las carpinterías que los usuarios llevan a cabo de manera individual. Así, en el estado inicial se reduce la demanda energética de calefacción de 110,96 [E] a 99,64 kWh/m²año [E]. Teniendo en cuenta el rendimiento y tipo de combustible de las instalaciones individuales, también el consumo de energía primaria se reduce de 258,10 [F] a 240,37 kWh/m²año [E] y la calificación energética de emisiones, de 88,60 [G] a 81,60 kCO2/m²año [G]. Tras la rehabilitación, las nuevas características de la edificación dan lugar a una calificación parcial de demanda energética de calefacción de 53,35 kWh/m²año [D], una calificación parcial de consumo de energía primaria de 130,22 kWh/m²año [E] y una calificación energética de emisiones de $27,51 \mathrm{kCO}_{2} / \mathrm{m}^{2}$ año [E]. Estos valores suponen una mejora importante de la eficiencia energética, con una reducción de la demanda de calefacción y de consumo de energía primaria de un $46 \%$ y una reducción de emisiones globales de un 66\%.

Tabla 2. Variación de eficiencia energética de la edificación de referencia (Bloque 1DEFG) entre estado inicial y estado modificado

\begin{tabular}{lrrr}
\hline & ESTADO INICIAL & \multicolumn{1}{c}{ ESTADO } \\
& ModifICADO \\
& $\begin{array}{l}\text { Estado de } \\
\text { proyecto }\end{array}$ & $\begin{array}{c}\text { Estado previo } \\
\text { intervención }\end{array}$ & \\
\hline Emisiones (kgCO2/m2año) & 88,60 & 81,60 & 27,51 \\
Consumo (kWh/m2año) & 258,10 & 240,37 & 130,22 \\
Demanda calefacción (kWh/m2año) & 110,96 & 99,64 & 53,35 \\
Demanda refrigeración (kWh/m2año) & 6,35 & 10,34 & 9,30 \\
\hline
\end{tabular}

Fuente: Elaboración propia.

Estos resultados confirman que las soluciones de rehabilitación llevadas a cabo en la envolvente de la edificación alcanzan unos parámetros óptimos de consolidación, homogeneidad y mejora de las condiciones de confort y la eficiencia energética luego, aunque no suponen una innovación tecnológica, resultan eficaces y constituyen un referente del tipo de actuaciones que habitualmente se han realizado en este tipo de edificios y contextos urbanos. Por otra parte, junto al añadido de volúmenes para mejorar la accesibilidad en los bloques y torres, estas medidas contribuyen a aportar una nueva imagen al conjunto. Su importancia funcional, que contribuye a integrar el área en el mercado inmobiliario actual, contrasta con los criterios compositivos y formales que se aplican y con su efecto sobre la identidad arquitectónica de la obra. La idea de proporcionar un tratamiento unitario a las distintas tipologías, en este caso no considera su afinidad con el proyecto original ni fomenta la valoración de su imagen urbana, reconocida por la historiografía de la arquitectura desde sus primeros años.

\footnotetext{
33 Se utiliza el programa CE3X, con introducción de datos mediante valores conocidos y estimados a partir del Proyecto de Ejecución para la Rehabilitación de 32 viviendas y locales en Avenida de Nuestra Señora de Valvanera n. 320 del P. D. de Caño Roto, de E. Hernández Fernández, J. L. López Delgado y G. Ruiz Palomeque, 1997 (Archivo particular CREA arquitectos, Madrid. Sin signatura). Las principales variaciones en parámetros que intervienen en la eficiencia energética del edificio, además de los vinculados a las características térmicas de la envolvente que se han descrito a lo largo del artículo, son las siguientes. En referencia a la disposición y orientación, la superficie habitable varía en el estado inicial de 2.063,00 $\mathrm{m}^{2}$ a 2.107,00 $\mathrm{m}^{2}$ y pasa en el estado modificado a 2.319,00 $\mathrm{m}^{2}$; el factor de sombra de los huecos varía en el estado inicial de un $16,00 \%$ en fachada norte y un $20,20 \%$ en fachada sur, a un $36,60 \%$ y un $23,70 \%$ respectivamente, valores que se mantienen en el estado modificado. En cuanto a las instalaciones térmicas, se introducen con el supuesto de que en el estado inicial se mantiene el sistema de generación de calefacción y ACS original de carbón y en el estado modificado se incorporan calderas mixtas individuales de gas natural.
}

ACE, 14 (42) CC BY-ND 3.0 ES | UPC Barcelona, España | La envolvente en la rehabilitación de conjuntos de vivienda 


\section{Conclusiones}

Intervenciones integrales como la rehabilitación de la edificación del Poblado Dirigido de Caño Roto aportan a la envolvente unas condiciones funcionales actualizadas, que suponen importantes mejoras en la habitabilidad y beneficios energéticos, y contribuyen a la renovación del parque edificatorio a escala urbana. El propio proceso de rehabilitación contribuye a la reducción del impacto ambiental en el sector de la edificación, tan importante para el cumplimiento de los compromisos internacionales enfocados a conseguir un futuro bajo en carbono. A pesar de ello, se trata de unas intervenciones que no cuentan con una normativa específica, debiendo regirse por la existente para obra de nueva planta. Por otra parte, su relativa novedad y el escaso interés que en general se concede a la edificación original, llevan a cuestionar las pautas y principios derivados del criterio arquitectónico que rige su transformación.

Las cubiertas y fachadas, elementos de la envolvente más expuestos a los agentes externos, se consolidan y optimizan como barreras térmicas con la superposición o el trasdosado por el exterior de nuevos sistemas. Esta solución, una de las más empleadas en rehabilitación, comporta una serie de beneficios:

- en la gestión, al permitir que los vecinos permanezcan en su vivienda durante la obra.

- en la ejecución, al conservar lo existente sin desmontarlo.

- en la estabilidad y conservación, al evitar la degradación de los materiales originales de fachada.

- en el funcionamiento tipológico, al mantener la superficie útil de las viviendas.

- en el comportamiento higrotérmico, al mejorar la estanqueidad y el aislamiento, eliminar puentes térmicos y humedades de condensación y limitar las pérdidas o ganancias de calor.

- en el comportamiento energético, al mantener toda la masa del edificio en el interior, permitiendo el aprovechamiento de su inercia térmica para el almacenamiento de energía en invierno.

- en la población, al combatir situaciones de pobreza energética, tan habituales en estos conjuntos residenciales, con un incremento del confort que no va necesariamente acompañado de una reducción de consumo, pero sí de emisiones.

En paralelo a estas cuestiones derivadas del funcionamiento y la eficiencia de la edificación, para la rehabilitación de estos conjuntos residenciales, deberían asimismo tenerse en cuenta valores de tipo histórico, compositivo y urbanístico. En la actualidad, actuaciones como la tratada en el Poblado Dirigido de Caño Roto, buscan fundamentalmente aportar una nueva imagen unitaria de conjunto urbano, desde nuevos parámetros compositivos y formales. Sin embargo, se plantea si para acometer su rehabilitación, o cualquier intervención en un conjunto residencial con un determinado interés arquitectónico, deberían demandarse tratamientos de carácter conservativo y afín a sus valores ambientales, acordes al espíritu con el que fuera construido. La desprotección patrimonial de estos bienes y la falta de regulación específica para este tipo de rehabilitación ponen de relieve la necesidad de una toma de conciencia global que vincule aspectos relacionados con la habitabilidad y la eficiencia con el concepto de patrimonio urbano histórico, para desencadenar una ampliación de la normativa que defina baremos y criterios de actuación, y permita implementar vías de protección.

\section{Agradecimientos}

Financiado por el Gobierno de Aragón. Grupo de Investigación en Arquitectura (GIA) (Referencia Grupo T37_17R).

Conflicto de intereses: La autora declara que no hay conflicto de intereses. 


\section{Bibliografía}

ANDIMA et al. (2008). Guía de rehabilitación energética de edificios de viviendas. Madrid, España: ANDIMA y Comunidad de Madrid. Recuperado de http://www.madrid.org/bvirtual/BVCM005835.pdf

Blos, D. (1999). Los polígonos de vivienda social: Perspectivas hacia su recuperación en España, Francia y Brasil (Tesis doctoral). Universitat Politècnica de Catalunya, Barcelona. Recuperado de https://upcommons.upc.edu/handle/2117/93441

Campos-Sánchez, F. S.; Abarca-Álvarez, F. J. y Domingues, A. (2018). Sostenibilidad, planificación y desarrollo urbano: en busca de una integración crítica mediante el estudio de casos recientes. ACE: Architecture, City and Environment, 12(36), 39-72. DOI: http://dx.doi.org/10.5821/ace.12.36.5145

Cánovas Alcaraz, A. y Ruiz Bernal, F. (2013). Caño Roto: Vázquez de Castro, iñiguez de Onzoño. Madrid, España: Ministerio de Fomento y CEDEX.

Casals Tres, M. y Arcas Abella, J. (2010). Habitabilidad, un concepto en crisis. Sobre su redefinición orientada hacia la rehabilitación. En: Actas del SB1Omad Sustainable building conference, (Madrid, 28 al 30 de abril). Madrid, España: SB10mad. Recuperado de http://www.sb10mad.com/ponencias/

Cuchí, A. y Sweatman, P. (2014). Informe GTR. Estrategia para la rehabilitación. Claves para transformar el sector de la edificación en España. Madrid, España:. Grupo de Trabajo sobre Rehabilitación. Recuperado

de https://www.gbce.es/archivos/ckfinderfiles/GTR/Informe\%20GTR\%202014.pdf

De Luxán García de Diego, M. et al. (2010). Metodología de Evaluación para el Programa de Ayudas a las Actuaciones de Rehabilitación para la Mejora de la Sostenibilidad y Eficiencia Energética de las Edificaciones. En: Actas del SB10mad Sustainable building conference, (Madrid, 28 al 30 de abril). Madrid, España: SB10mad. Recuperado de http://www.sb10mad.com/ponencias/

Díaz Gómez, C. (1986). Aproximació a l'evolució i al comportament derivat de les tècniques constructives utilitzades en els tipus edificatoris exempts destinats a habitatge econòmic a Catalunya (Període 1954-1976) (Tesis doctoral). Universitat Politècnica de Catalunya, Barcelona. Recuperado de https://upcommons.upc.edu/handle/2117/93439

Díaz, C.; Cornadó, C.; Vima-Grau, S.; Ravetllat, P. J. y Garcia-Almirall, P. (2019). Intervenciones de rehabilitación en grandes conjuntos habitacionales construidos durante el periodo 1950-1975. ACE: Architecture, City and Environment, 14(41), 11-34. DOI: http://dx.doi.org/10.5821/ace.14.41.6538

Díez de Pablo, A. (2015). La vivienda social como patrimonio urbano. Análisis de la patrimonialización de tres Barrios de Promoción Oficial madrileños (Tesis doctoral). Universidad Politécnica de Madrid, Madrid. Recuperado de http://oa.upm.es/39877

F. Galiano, L.; F. de Isasi, J. y Lopera Arazola, A. (1989). La Quimera moderna. Madrid, España: Hermann Blume.

Fullaondo, J. D. (1969). José Luis Íñiguez de Onzoño. Nueva Forma, 37, 3-35.

IDAE. (2011). Guía práctica de la energía: consumo eficiente y responsable. Madrid: IDAE Recuperado de https://www.idae.es/uploads/documentos/documentos 11406 Guia Practica Energia 3ed A2010 509f8287.pdf 
IDAE. (2017). Balances Energéticos Anuales. Periodo: 1990-201. Recuperado de http://sieeweb.idae.es/consumofinal/

Kurtz, F., Monzón, M. y López-Mesa, B. (2015). Obsolescencia energética y acústica en la vivienda social de la postguerra española en áreas urbanas vulnerables. El caso de Zaragoza. Informes de la construcción, 66(extra-2), 19-36. DOI: http://dx.doi.org/10.3989/ic.14.062

Moya González, L. y Díez de Pablo, A. (2012). La intervención en la ciudad construida: acepciones terminológicas. Urban, NS04, 113-122. Recuperado de http://polired.upm.es/index.php/urban/article/view/1870

Ministerio de Fomento (2010). Código Técnico de la Edificación. Catálogo de Elementos Constructivos. Recuperado de https://www.codigotecnico.org/index.php/menu-catalogoinformatico-elementos-constructivos.html

Ministerio de Fomento (2017). Código Técnico de la Edificación. Documento Básico HE Ahorro de Energía. Recuperado de https://www.codigotecnico.org/index.php/menu-ahorro-energia.html

Quesada, F. (2018). Desarrollo de nuevos métodos de Evaluación Sustentable de la edificación a partir de la revisión del Estado del Arte. ACE: Architecture, City and Environment 13 (37), 51-70. DOI: http://dx.doi.org/10.5821/ace.13.37.4871

Rubio del Val, J. y Molina Costa, P. (2010). Estrategias, retos y oportunidades en la rehabilitación de polígonos de vivienda. Revista Ciudades, 13, 15-37. DOI: https://doi.org/10.24197/ciudades.13.2010.15$\underline{37}$

Ruiz Palomeque, L.G. (2001). Rehabilitación integral del Poblado Dirigido de Caño Roto, Madrid. Un modelo de intervención en grandes conjuntos urbanos. En: Premios Calidad Arquitectura y Vivienda. Comunidad de Madrid 99+98 (pp. 146-151). Madrid, España: Consejería de Obras Públicas Comunidad de Madrid.

Sambricio, C. (2000). De la arquitectura del nuevo Estado al origen de nuestra Contemporaneidad: el debate sobre la vivienda en la década del cincuenta. Revista de Arquitectura, 4, 75-90.

Tejedor Bielsa, J. (2015). Nuevo paradigma normativo sobre la ciudad: Retornando a la ciudad tradicional. Informes de la Construcción, 67(extra-1), 53-70. DOI: http://dx.doi.org/10.3989/ic.14.046

Windows \& Daylighting. Building Technology \& Urban Systems. (2019). THERM Finite Element Simulator. Recuperado de https://windows.lbl.gov/software/ 